\title{
Research Article \\ Effect of Nitrogen Implantation on Metal Transfer during Sliding Wear under Ambient Conditions
}

\author{
Luke Autry and Harris Marcus \\ Department of Chemical, Materials and Biomolecular Engineering, Institute of Materials Science, University of CT, Storrs, \\ CT 06269, USA \\ Correspondence should be addressed to Luke Autry; autch97@gmail.com
}

Received 21 September 2012; Accepted 3 December 2012

Academic Editor: Patrick De Baets

Copyright (C) 2013 L. Autry and H. Marcus. This is an open access article distributed under the Creative Commons Attribution License, which permits unrestricted use, distribution, and reproduction in any medium, provided the original work is properly cited.

\begin{abstract}
Nitrogen implantation in Interstitial-Free steel was evaluated for its impact on metal transfer and $1100 \mathrm{Al}$ rider wear. It was determined that nitrogen implantation reduced metal transfer in a trend that increased with dose; the Archard wear coefficient reductions of two orders of magnitude were achieved using a dose of $2 \mathrm{e} 17 \mathrm{ions} / \mathrm{cm}^{2}, 100 \mathrm{kV}$. Cold-rolling the steel and making volumetric wear measurements of the Al-rider determined that the hardness of the harder material had little impact on volumetric wear or friction. Nitrogen implantation had chemically affected the tribological process studied in two ways: directly reducing the rider wear and reducing the fraction of rider wear that ended up sticking to the ISF steel surface. The structure of the nitrogen in the ISF steel did not affect the tribological behavior because no differences in friction/wear measurements were detected after postimplantation heat treating to decompose the as-implanted $\varepsilon-\mathrm{Fe}_{3} \mathrm{~N}$ to $\gamma-\mathrm{Fe}_{4} \mathrm{~N}$. The fraction of rider-wear sticking to the steel depended primarily on the near-surface nitrogen content. Covariance analysis of the debris oxygen and nitrogen contents indicated that nitrogen implantation enhanced the tribo-oxidation process with reference to the unimplanted material. As a result, the reduction in metal transfer was likely related to the observed tribo-oxidation in addition to the introduction of nitride wear elements into the debris. The primary $\mathrm{Al}$ rider wear mechanism was stick-slip, and implantation reduced the friction and friction noise associated with that wear mechanism. Calculations based on the Tabor junction growth formula indicate that the mitigation of the stick-slip mechanism resulted from a reduced adhesive strength at the interface during the sticking phase.
\end{abstract}

\section{Introduction}

Metal transfer is an insidious process occurring during sliding of metallic contacts that can result in galling $[1,2]$ as defined by ASTM [3]. The traditional model of metal transfer usually starts with adhesive wear events between interacting asperities. Fractured metal from the cohesively weaker material transfers to the stronger material. As a result, small particles or "transfer elements" of transferred material are stuck on the harder materials surface. The individual fragments of the transferred material resulting from an isolated tribo-interaction are known as "transfer elements." A transfer element acts like an additional asperity that can continue to interact with the softer material and build-up into a multi-particle debris through a process known as "Mutual Material Transfer" $[4,5]$. Metal transfer results in protrusions of the softer material on the harder materials surface. On subsequent passes on the wear track this results in a change in wear mechanism; the softer material ends up also sliding against work hardened and oxidized protrusions of the same material resulting in a change of friction coefficient. For an excellent example of this phenomenon, see the wear studies based on sheet metal drawing $[1,6]$. In the worst case, the protrusions continue to build up on subsequent passes until the surface has "galled." Qualitative galling tests rely on the accumulation of material from one surface to another during continuous contact sliding $[7,8]$, and the galling criterion is subjective. Typically, if the surface roughens because of material transfer, galling occurs at that particular load for the test. Quantitative tests are based on measuring the coefficient of friction $[9,10]$ where the galling load is the load at which the coefficient of friction rapidly increases. At the heart of 
galling is metal transfer, and this why there is a need to study the influence of different surface treatments on its severity.

In the past 30 years, researchers have studied ion implantation for the modification of tribosurfaces $[11,12]$. In the case of pure iron $[13,14]$ and some types of steels [15] nitrogen ion implantation hardens the surface via nitride formation. In some cases, 3- $4 x$ relative improvements in the microhardness of the surface of steels using a Knoop indenter were observed [16]. The modification of the surface results in improved abrasive [15-17] and adhesive [18, 19] wear resistance. The improvement in the abrasive wear resistance is obviously because of the surface hardening via implantation. However, for adhesive wear regimes the mechanism for improvement is not so obvious. The environment and any films/layers formed on either surface affect adhesive wear resistance. In addition, the hardness properties of the implanted surface and its counter material may be important when phenomena such as junction growth and deformation-induced surface, roughening [20] are considered. These various factors work together to influence the adhesive wear resistance of a surface and as a result it makes fundamentally studying the adhesive wear resistance of an implanted surface difficult.

The Archard wear equation is a good starting point for discussing adhesive wear for full plastic contact. The volume of material removed per unit sliding length is

$$
\frac{V}{x}=k \frac{W}{H}
$$

where $W$ is the applied load and $H$ is the hardness of the softer material. Note that hardness is the load divided by the projected area on the indented surface of the indentation. The constant $k$ is often interpreted as the probability of two touching asperities producing a wear event. Fixing constant $k$ shows that increasing the load or reducing the softer materials hardness increases the wear rate due to the increase in real contact area, $A_{\text {real }} \approx(W / H)$. In this case, indentation of the softer material by the asperities of the harder surface is occurring. The indentation area between the harder material and softer material is equal to the projected area of the indented interface onto the flat surface. The plasticity index (The equivalent roughness parameters used for this analysis determined by optical profilometry were $R_{a}=0.095 \mu \mathrm{m}$ and $\rho=25 \mu \mathrm{m}$. The hardness of the $1100 \mathrm{Al}$ was $441 \mathrm{Mpa}(\mathrm{HK})$. The Young Modulus/Poisson Ratio for Fe and Al were taken from their elemental values.) in this case is 6.5 indicating that full plastic contact is occurring at the surface and that the $W / H$ approximation for the real contact area is appropriate.

The validity of using (1) to analyze wear data depends on the type of wear that occurs. For pure hard on soft adhesive wear (1) is a suitable empirical relationship. However, as noted by Rigney [21], the hardness of the harder surface could also affect the wear regime. Examples of this are found with steelon-steel wear studies where the hardness of the disk varied by changing the tempering conditions [22]. Borland and Bian [23] created an alternative to the Archard wear equation by defining a variable known as the "index of wear intensity," which was a function of the "equivalent hardness"- $H_{\mathrm{eq}}$. In that study, a linear combination of the hard and soft material hardness values defined $H_{\mathrm{eq}}$. The index of wear intensity, $I$, was used in an exponential relationship to relate wear rate to harder materials hardness:

$$
\frac{V}{x}=a \exp ^{(b I)}
$$

where $I$ is the index wear intensity given by $I=(W s) / H_{\mathrm{eq}}$. $s$ is the sliding velocity. $a$ and $b$ are fitted parameters. The advantage of modeling wear rate by using an exponential relationship is that mild and severe wear regimes can be captured by one relationship. The linear relationship given by (1) breaks down at a mean contact pressure of $\approx H_{\text {soft }} / 3$ and the wear rate exponentially increases with load. The equivalent hardness used by Borland has the disadvantage that, as the hardness of the harder material becomes much larger than that of the softer material, the $H_{\mathrm{eq}}$ becomes $\approx \mathrm{CH}_{\mathrm{Hard}}$ and can underpredict the wear rate. This study proposes the following alternative expression for $H_{\mathrm{Eq}}$ while using (1) for the basic wear equation:

$$
H_{\text {eq }}=\frac{H_{\text {hard }} H_{\text {soft }}}{H_{\text {hard }}+H_{\text {soft }}} \text { or } \frac{1}{H_{\text {eq }}}=\frac{1}{H_{\text {hard }}}+\frac{1}{H_{\text {soft }}} .
$$

The use of this form for $H_{\mathrm{eq}}$ is justified because in the extreme case $H_{\text {hard }} \rightarrow \infty, H_{\text {eq }} \rightarrow H_{\text {soft }}$ describes the case of a rigid indenter penetrating into soft material. Therefore, $A_{\text {real }} \approx W / H_{\text {eq }}=W / H_{\text {soft }}$, which was used in the derivation of (1). When $H_{\text {hard }} \rightarrow H_{\text {soft }}, H_{\text {eq }} \rightarrow\left\{H_{\text {soft }} / 2\right\}$ resulting in both asperities bilaterally deforming with no indentation of either surface occurring. This gives the second limiting case of $A_{\text {real }} \approx W / H_{\mathrm{eq}}=\{2 W / H\}$, which is close to that predicted by a plane stress model of a square asperity against a flat surface without shear stresses: $(3 \mathrm{~W} / \mathrm{H})$. In the presence of shear stresses, the real contact area is larger than $\{3 W / H\}$ (This argument is based on using the Von Mises Criterion in plane stress: $\sigma_{11}^{2}+3 \sigma_{12}=\sigma_{y}^{2}$. Note that in the expression $H \approx 3 \sigma_{y}$ and $\sigma_{11}=W / A$ were used. In addition, shear stresses were absent: $\sigma_{12}=0$.) as predicted by the Tabor Junction Growth Model, and hence the accuracy of the $W / H$ approximation for $A_{\text {real }}$ should get worse. For intermediate $H_{\text {hard }}$ ranges, $\infty>H_{\text {hard }}>H_{\text {soft }}$, a combination of indentation and junction growth can be thought to occur. Unfortunately, no publication of a full plastic, asperity contact analysis where both surfaces are yielding is available to date, but it is likely that the real contact area will be between $W / H$ and $3 W / H$.

In a system in which adhesive wear dominates, material hardness is important in that it influences the contact area. In this paper, (3) modifies the Archard Wear equation (1) by using (3) for $H$ :

$$
\frac{V}{X}=k \frac{W}{H_{\mathrm{eq}}}=a+\frac{b}{H_{\mathrm{hard}}} .
$$

The empirical coefficients $a$ and $b$ are determined by $V / X$ versus $H_{\text {hard }}$ regression analysis for a given set of testing conditions. Notice that, since $W$ is a constant, it was lumped into $a\left(=k W / H_{\text {soft }}\right)$ and $b(=k W)$. The wear coefficient determined by $b / W$ or $a H_{\text {soft }} / W$ is equal to an averaged Archard wear coefficient over the series of fit data. The study 
will evaluate $V / X$ versus $H_{\text {hard }}$ for a series of work-hardened, unimplanted ISF steel samples in order to determine how the wear rate changes with harder material hardness. If the results of the unimplanted tests validate (4), then using (4) to adjust the hardening effect of ion implantation is valid. This paper reports the rider wear rates $(V / X)$ and percentage of rider wear ending up as metal transfer for unimplanted and implanted conditions. With the aforementioned regression analysis and using surface analysis techniques this paper will show the effect of chemical modification by ion implantation.

The reduction in adhesion between the surfaces is estimated by measuring friction coefficient. Assuming that adhesive wear dominates, which is a reasonable assumption if the surface roughnesses are controlled, the Tabor Junction Growth formula [24] relates shear strength at the interface and bulk yield strength to the maximum friction coefficient during sliding:

$$
\mu=\frac{1}{2 \sqrt{\left(s_{o} / s_{i}\right)^{2}-1}},
$$

where $s_{o}$ is the yield shear strength of the bulk and $s_{i}$ is the shear strength of the interface. Rearranging (5) allows the interfacial shear strength to be deduced. This model is valid when considering the stick-slip mechanism of adhesive wear where junctions are dynamically interacting in the following order: welding, transmitting shear stress, growing, and eventually delaminating or separating. Equation (5) applies during the junction growth phase, which is when most of the shear stresses transmit across the interface. Since the measured friction coefficient is a composite of all the types of asperity interactions, friction coefficients are by nature noisy. This paper reports the average friction coefficient $\mu_{\text {ave }}$ and standard deviation of the noise. The $\mu_{\text {ave }}$ plus the standard deviation of the noise is used to calculate the interfacial shear strength through (5) because during the junction growth phase the shear strength at the interface is a maximum.

\section{Methodology}

The implantations were carried out using two separate ion implantation laboratories: the University of Michigan Ion Beam Laboratory (MIBL) and the University of Albany (SUNY) Ion Beam Laboratory. The ion implanter used at the University of Michigan was a $400 \mathrm{kV}$ piecemeal implanter with the ion source manufactured by Danfysik, the ion accelerator manufactured by National Electrostatics Corp., and the implantation stage manufactured by High Volatge Engineering Europa. The implanter used at the SUNY Ion Beam Laboratory was a 400-Kilovolt Varian (Extrion) 400-10A Implanter. Nitrogen gas was used as the implanter ion source material. The current was kept between 50 and $75 \mu \mathrm{A}$. At those currents, the sample temperature was not expected to exceed $200^{\circ} \mathrm{C}$; this prediction was based on a heat balance using the beam energy as the heat input and blackbody radiation as the heat output. Several dose/energy combinations were used for these experiments. Ion doses ranged from $5 \mathrm{e} 16$ ions $/ \mathrm{cm}^{2}$ to $2 \mathrm{e} 17$ ions $/ \mathrm{cm}^{2}$. Two acceleration energies were used: $100 \mathrm{kV}$ and $50 \mathrm{kV}$. In addition, precold rolling the

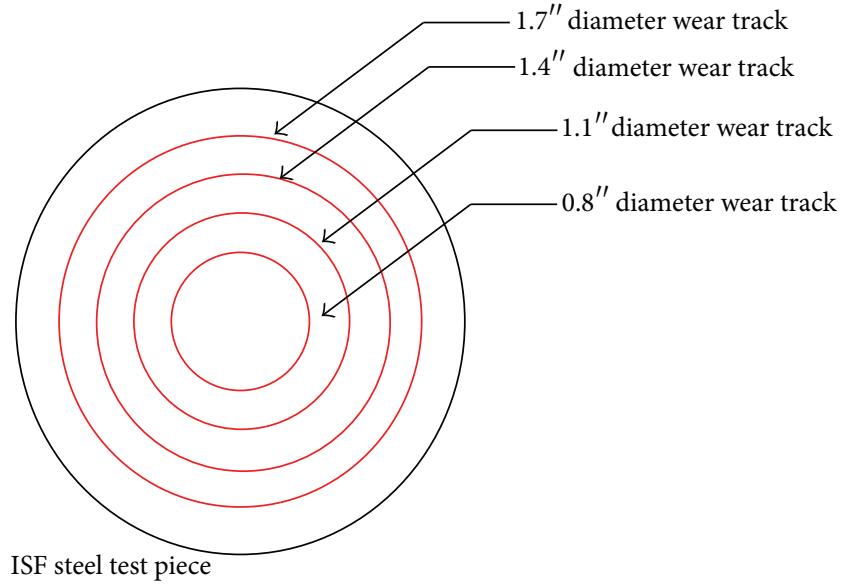

FIGURE 1: An example of the wear tracks used for the unimplanted samples. Note the nitrogen-implanted sample had an extra wear track.

ISF steel prior to implantation was performed on two samples in order to provide extra hardening.

The samples used for this experiment were Interstitial Free Steel (ISF) with a chemistry of (in Wt\%) $0.0014 \%$ C, $0.12 \% \mathrm{Mn}, 0.034 \% \mathrm{Al}, 0.038 \% \mathrm{Ti}$, and the balance $\mathrm{Fe}$. The measured Knoop hardness (HK) of this material was $92 \pm$ $6\left(\mathrm{gf} / \mathrm{mm}^{2}\right)$. The $1100 \mathrm{Al}$ had chemistry of (in Wt\%) $0.05 \%$ $\mathrm{Cu}, 0.35 \% \mathrm{Fe}, 0.25 \% \mathrm{Si}$, and the balance $\mathrm{Al}$ with a $\mathrm{HK}$ of $48 \pm 4$. The ISF Steel was ground with 600 grit and chemically polished using a 7\% (by Vol.) HF solution with a balance of $\mathrm{H}_{2} \mathrm{O}_{2}$ (30\% vol. concentration). The solution was kept at temperature $25-20^{\circ} \mathrm{C}$ using packed ice. The resulting finish (RMS) of the samples (as checked by an optical profilometer) was $0.01-0.08 \mu \mathrm{m}$ when inspected over $50 \mu \mathrm{m}$ lengths. The $1100 \mathrm{Al}$ samples were received in the form of $1 / 8^{\prime \prime}$ Dia. balls with an HK of $38 \pm 4\left(\mathrm{gf} / \mathrm{mm}^{2}\right)$. Prior to testing, the samples were chemically polished by a solution composed of $75 \%$ (by vol.) phosphoric acid, 5\% nitric acid, and $20 \% \mathrm{H}_{2} \mathrm{O}$. The temperature of the solution was kept $200-210^{\circ} \mathrm{F}$ during the process. The resulting RMS of the samples was $0.05-0.11 \mu \mathrm{m}$ when inspected over $50 \mu \mathrm{m}$ lengths.

The single pass wear testing was performed using a Falex multispecimen wear tester. The speed setting was 1 RPM, and the load setting was $3 \mathrm{lbs}$. (Because the $1100 \mathrm{Al}$ pin was tested on different diameter tracks, the pin speed varied by at most a factor of 3.4. Pin speed variations between the five wear tracks were not a factor in friction measurements, as the coefficient of friction did not measurably vary from track to track. This was likely due to the test speed being kept at 1 RPM. This implies that the speed variations did not significantly affect the working hardening rate of the $1100 \mathrm{Al}$. Al-K $\alpha$ EDS mapping did not reveal and differences surface area coverage between different tracks.) A 3 lbs. load was chosen because it maximized the amount of metal transfer without tearing out the ball bearing from its mount. A pneumatic pressure sensor controlled the load to within $0.1 \mathrm{lbs}$. For the unimplanted samples, the traced tracks on the sample were at the following diameters: $1.7^{\prime \prime}, 1.4^{\prime \prime}, 1.1^{\prime \prime}$, and $0.8^{\prime \prime}$ giving an 


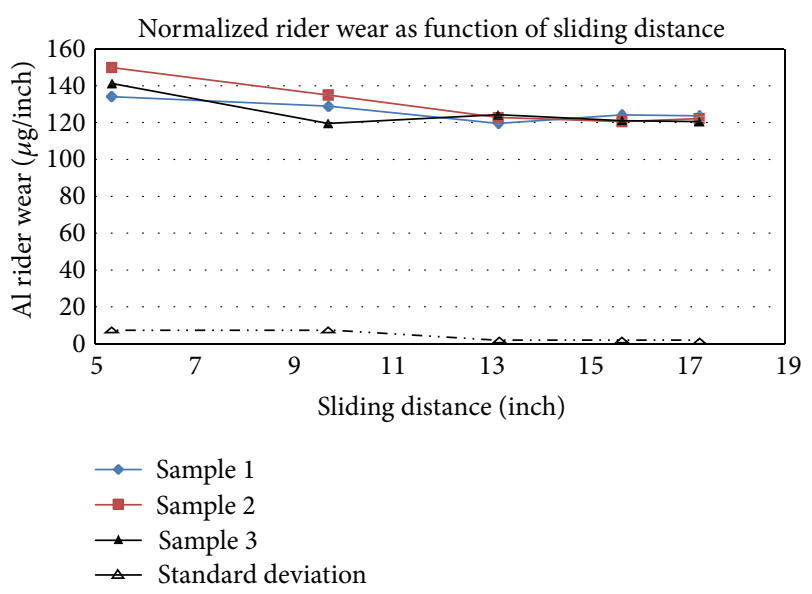

FIGURE 2: Plot of $1100 \mathrm{Al}$ rider wear versus siding distance for three unimplanted ISF steel.

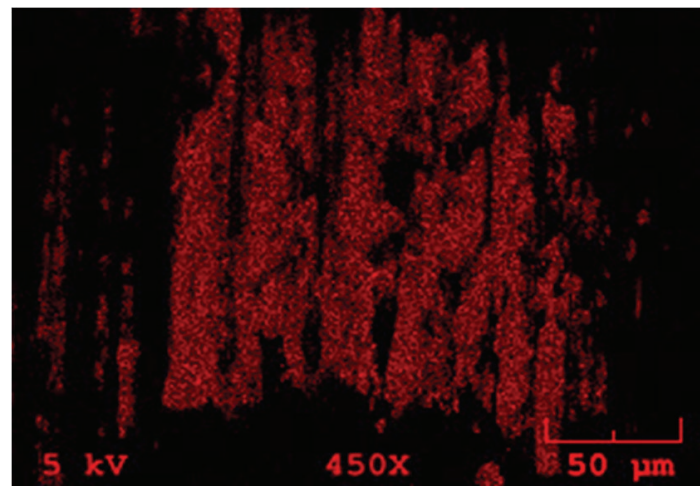

FIGURE 3: Al-K $\alpha$ EDS map for the 3 lbs single-pass wear test.

effective sliding distance of $15.7^{\prime \prime}$. The N-implanted samples had five tracks $\left(1.7^{\prime \prime}, 1.4^{\prime \prime}, 1.1^{\prime \prime}, 0.8^{\prime \prime}\right.$, and $0.5^{\prime \prime}$ in diameter) giving an effective sliding distance of $17.3^{\prime \prime}$. An schematic of the wear tracks is provided in Figure 1. During sliding the friction coefficient was measured using a $10 \mathrm{lbs}$ load cell with an error of $0.01 \mathrm{lbs}$ offset $3^{\prime \prime}$ from center of rotation. After sliding, the $1100 \mathrm{Al}$ rider and ISF Steel plates were reweighed. The metal transfer and rider wear rates were determined by the weight difference from before and after the wear tests using a Mettler Toledo micro balance with an accuracy of $\pm 4 \mu \mathrm{g}$. Using a large load and long track lengths as described above the balance error impacts on the weight changes were minimized. Other sources of error in the wear experiment come from the repeatability of the wear experiment due to errors in load/speed control and variability in the surface conditions such as roughness/chemistry differences. Wearing gloves during handling and storing the samples in dry desiccators under $0.5 \mathrm{~atm}$ pressure controlled the surface chemistry variation.

Due to the quantitative nature of this study, the reproducibility error of the single-pass wear experiments needed to be established. Using three unimplanted ISF steel samples with three $1100 \mathrm{Al}$ rider counter materials, the weight change of each $1100 \mathrm{Al}$ rider as a function of sliding distance was monitored in order to establish the reproducibility error of the wear tests. Figure 2 illustrates the results from the wear tests. At the smallest sliding distance, the reproducibility of the normalized $(\mu \mathrm{g} / \mathrm{inch})$ rider wear is the most poor as the standard deviation was the highest. As the sliding distance increased the reproducibility improved, and the standard deviation changed very little after a $13^{\prime \prime}$ sliding distance. The two major sources of error at small sliding distances are local ISF steel roughness and chemical variations. In addition, the decrease in the average normalized rider wear from $142 \mu \mathrm{g} /$ inch (at a $5.3^{\prime \prime}$ sliding distance) to $127 \mu \mathrm{g} / \mathrm{inch}$ (at a $9.7^{\prime \prime}$ sliding distance) indicates that $\mathrm{Al}$ rider run-in effects were present in the early stages of sliding. Because of run-in, the $\mathrm{Al}$ rider developed a flat, which saw repeated contact as the wear tracks were changed. It should be noted that despite developing a flat the real contact area stays the same because the ISF steel surface does not experience run-in and is sufficiently rough to create full-plastic contact condition: plasticity index $>1$. Due to material constraints, such reproducibity tests were not possible at all testing conditions, and we assumed for this study that the same reproducibility error ( $2 \mu \mathrm{g} /$ inch) applies to all other tests.

The average height of the $\mathrm{Al}$ area coverage on the ISF steel surface was determined by evaluating the coverage area of five Al-K $\alpha$ EDS maps (see Figure 3 as an example) for each testing condition. Dividing the volumetric aluminum transfer to the ISF steel by the coverage area gives the average debris height. Adobe Photoshop determined the average redpixel intensity on the wear track $\left(I_{\text {wear, ave }}\right)$, which is on a scale of 1 to 256. In addition, the software also determined the total number of red pixels $\left(N_{\text {wear }}\right)$. The average red-pixel intensity $\left(I_{\text {ref, ave }}\right)$ and total number of red pixels $\left(N_{\text {ref }}\right)$ were determined for an $1100 \mathrm{Al}$ reference sample. The coverage area was determined by multiplying the area of the EDS map by $\left\{I_{\text {wear, ave }} N_{\text {wear }}\right\} /\left\{I_{\text {ref, ave }} N_{\text {ref }}\right\}$.

Prior to testing the ion implanted samples unimplanted samples with varying degrees of cold work provided by flatrolling were tested to determine how the hardness of the ISF steel affects metal transfer and to also provide a baseline 


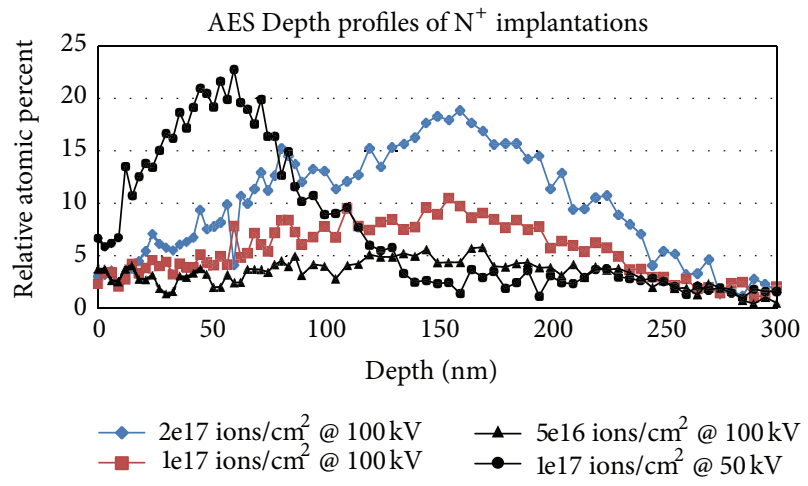

(a)
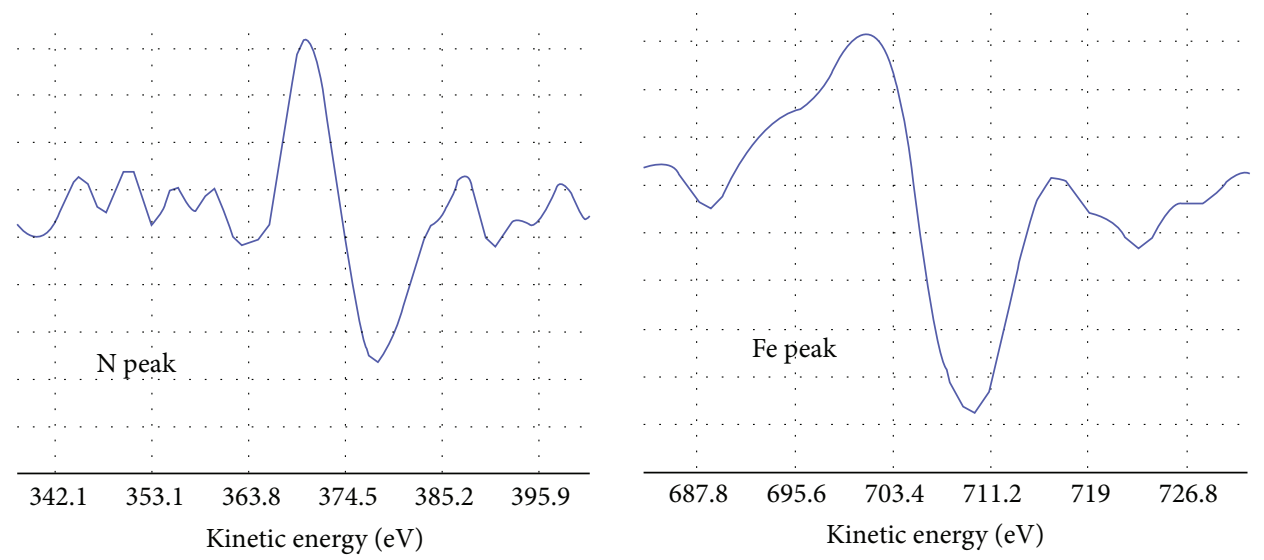

(b)

FIGURE 4: AES N depth profile and sample Auger peaks for four implantation conditions. Sample differentiated spectrums are provided in (b).

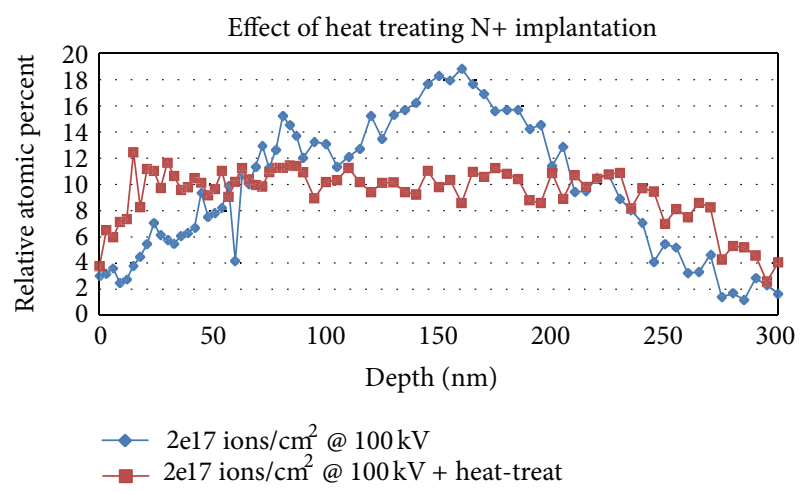

FIGURE 5: Depth profile of heat-treated $2 \mathrm{e} 17 \mathrm{ions} / \mathrm{cm}^{2}, 100 \mathrm{kV}$ compared to nonheat-treated sample implanted under same conditions.

that the $\mathrm{N}$-implanted samples could be compared to. The cold-rolled samples were rolled prior to grinding/chemical polishing and implantation if applicable.

The implantations were characterized using Auger Electron Spectroscopy (AES) with a PHI-590 Auger spectrometer with Ar ion beam depth profiling. The energy of electron probe was $3 \mathrm{kV}$, and the Ar ion beam energy was $1 \mathrm{kV}$.
The depth versus sputtering time was estimated using the following relationship:

$$
d=\frac{k C t}{\rho},
$$

where $k$ is the sputtering coefficient determined by a SRIM simulation, $C$ is the ion current density, and $\rho$ is the atomic packing density. The current was controlled 100-80 nA, which when rastered over a $1.5 \mathrm{~mm} \times 1.5 \mathrm{~mm}$ area yields a sputtering rate of 2-3 Ang/s.

A Bruker D5005 diffractometer using a Cu X-ray tube performed Glancing Angle X-Ray Diffraction (GAXRD) using a $1.5 \mathrm{deg}$. angle of incidence. A $1.5 \mathrm{deg}$. angle of incidence gave a $150 \mathrm{~nm}$ layer sensitivity $77-84 \%$ using kinematical diffraction theory (This calculation uses the formula derived by Rafaja [25] where it is assumed that the reflection intensity from a layer $d z$ is given by $d I=$ $I_{o} \exp \left\{-\mu z\left(\left(1 / \sin \left(\theta_{\text {incident }}\right)\right)+\left(1 / \sin \left(\theta_{\text {exit }}\right)\right)\right)\right\} d z . I_{o}$ is the reflection intensity of the top layer and $\mu$ is the mass absorption coefficient. The evaluated integration limits were $[0,150 \mathrm{~nm}]$ for the implantation layer and [0, $400 \mathrm{~nm}]$, where $400 \mathrm{~nm}$ reflects the maximum depth for a detectable reflection signal as determined by Beer's Law. The layer sensitivity is defined as $\left.\left(I / I_{o}\right)_{[0,150]} /\left(I / I_{o}\right)_{[0,400]} * 100\right)$. A Topcon-90 SEM with EDS capability analyzed the wear 


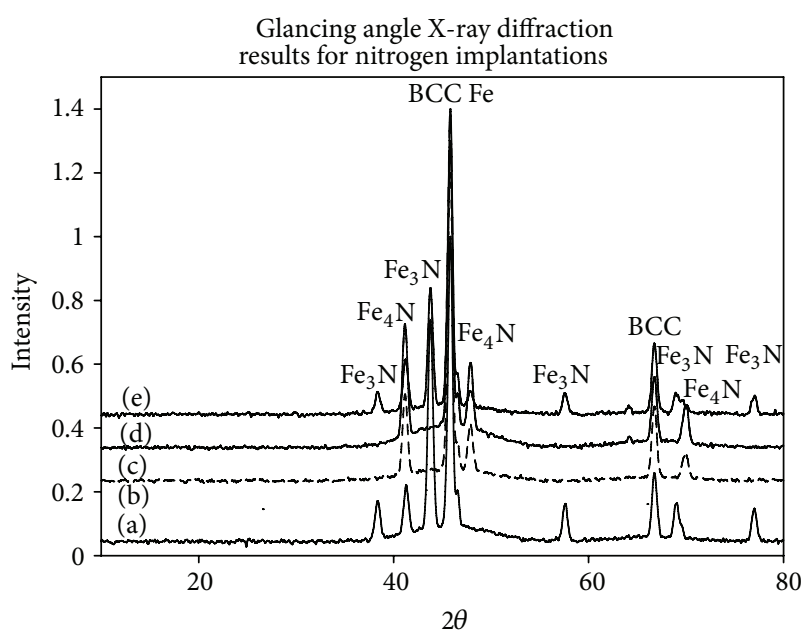
(a) - $2 \mathrm{e} 17 \mathrm{ions} / \mathrm{cm}^{2} ; 100 \mathrm{kV}$
(b) …. le17 ions $/ \mathrm{cm}^{2} ; 100 \mathrm{kV}$
(c) --- $5 \mathrm{e} 16$ ions $/ \mathrm{cm}^{2} ; 100 \mathrm{kV}$
(d) $-\cdots 2$ 2e17 ions $/ \mathrm{cm}^{2} ; 100 \mathrm{kV}$; heat-treat
(e) --- le17 ions $/ \mathrm{cm}^{2} ; 50 \mathrm{kV}$

(a)

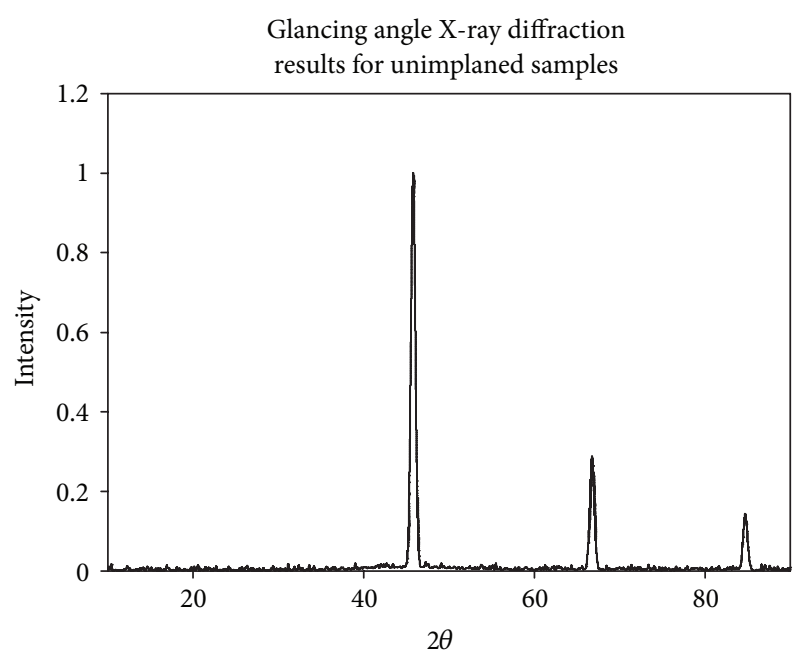

(b)

Figure 6: (a) Diffraction patterns of implanted surfaces using $\mathrm{Cu}$ $\mathrm{K} \alpha$ at a $1.5 \mathrm{deg}$. angle of incidence. (b) Diffraction patterns of unimplanted sample.

samples for debris morphology and chemistry. The electron acceleration used varied and is noted in this document. White light interferometry via a Zygo New-View 5000 determined the surface roughness.

\section{Results}

3.1. Implant Characterization. The AES depth profiles for the nitrogen implantations are in Figure 4. The N KLL peak at $380 \mathrm{eV}$ and Fe LVV (III) peak at $708 \mathrm{eV}$ were monitored during the depth profiling, and the peak intensities were determined by using the peak-to-peak height method with a differentiated spectrum. The relative atomic percent of nitrogen was evaluated by

$$
X_{N}=\frac{I_{N} / S_{N}}{\left(I_{N} / S_{N}\right)+\left(I_{\mathrm{Fe}} / S_{\mathrm{Fe}}\right)} \text {, }
$$

where $I$ is the peak intensity and $S$ is the peak sensitivity factor (determined from the Handbook of Auger Electron Spectroscopy, 3rd edition, Physical Electronics). As expected, the data shows that the peak concentration shifts towards the surface as the implantation energy reduces from $100 \mathrm{keV}$ to $50 \mathrm{keV}$, and the peak concentration increases with ion dose. The fact that the depth profiles still retain their Gaussian shape indicates that the samples were kept sufficiently cool during the implantation to limit diffusion. The depth profile of the heat-treated $\left(200^{\circ} \mathrm{C}, 1 \mathrm{hr}\right.$ in a stainless steel-canned argon environment) $2 \mathrm{el}$ ions $/ \mathrm{cm}^{2} ; 100 \mathrm{kV}$ sample is given in Figure 5. The depth profile shows a leveling of the as-implanted profile. AES analysis of the oxygen content revealed higher surface oxygen levels than the nonheattreated ones.

Figure 6(a) provides the GAXRD patterns for the implants, and Figure 6(b) has the reference unimplanted diffraction pattern. The pattern reveals the presence of $\gamma^{\prime}$ $\mathrm{Fe}_{4} \mathrm{~N}$ (cP5, Perovskite prototype) and $\varepsilon-\mathrm{Fe}_{3} \mathrm{~N}$ (hP4, NiAs prototype) in varying proportions depending on the implantation conditions. As one would expect, the proportion of $\mathrm{Fe}_{3} \mathrm{~N}$ peaks increased as the dose increased for constant ion energy. Annealing $\left(200^{\circ} \mathrm{C}, 1 \mathrm{hr}\right)$ the samples after implantation decreased the proportion of $\mathrm{Fe}_{3} \mathrm{~N}$ while increasing the $\mathrm{Fe}_{4} \mathrm{~N}$.

Other studies $[13,26,27]$ reported this decomposition of $\mathrm{Fe}_{3} \mathrm{~N}$ to $\mathrm{Fe}_{4} \mathrm{~N}$ due to postheat treatment and would be expected because the local $\mathrm{N}$ concentration is lowered. In addition to nitride peaks, $\alpha^{\prime}$ (BCT) martensite formed by $\mathrm{N}+$ implantation can be observed, which was evident from the $\{110\} \rightarrow\{110\}+\{101\}$ splitting of the BCC peaks. There was some disorder in the $1 \mathrm{el}$ and $2 \mathrm{e} 17 \mathrm{ions} / \mathrm{cm}^{2}$ implanted samples, which the amorphous humps beneath the $\{110\}$ BCC peaks indicate when compared to the unimplanted $\{110\}$ BCC peaks. The disorder is due to knock-on damage. The $200^{\circ} \mathrm{C}, 1 \mathrm{hr}$ anneal removed some of the disorder as the less pronounced amorphous hump indicates. As expected, the intensity of the amorphous relative to the $\{110\}$ BCC peak increased with ion dose and energy. It should also be noted that cold rolling had no measurable effect on the diffraction pattern; the diffraction pattern was solely determined by implantation. The nitrogen implantations also contained detectable $\mathrm{Fe}_{3} \mathrm{O}_{4}$ in the implantations with doses greater than $1 \mathrm{el}$ ions $/ \mathrm{cm}^{2}$. XPS and TEM studies have revealed that under ambient conditions $\mathrm{Fe}_{3} \mathrm{O}_{4}$ films form on polycrystalline iron [28]. The relative peak intensities of the $\mathrm{Fe}_{3} \mathrm{O}_{4}$ lines compared to the formed nitrides were the largest at the $2 \mathrm{e} 17$ dose implantation indicating that implantation promoted the growth of the oxide film following implantation.

Figures 7(a) and 7(b) contain SEM images of the wear debris transferred to the unimplanted, unrolled ISF steel. The amount of transferred wear debris was quite extensive. Using Archard's wear equation (1) to calculate the wear coefficient 


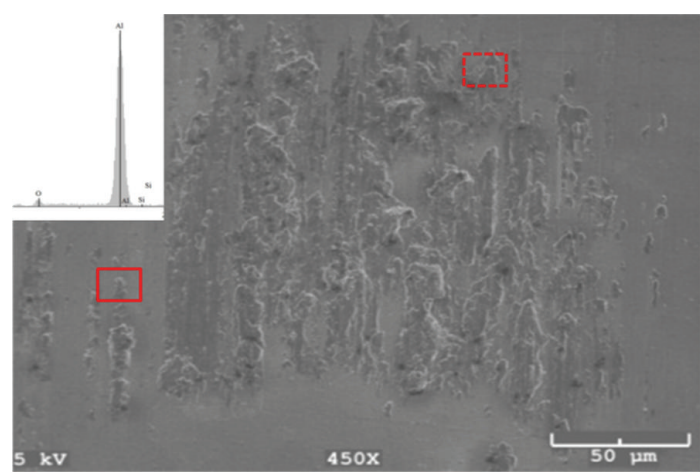

(a)

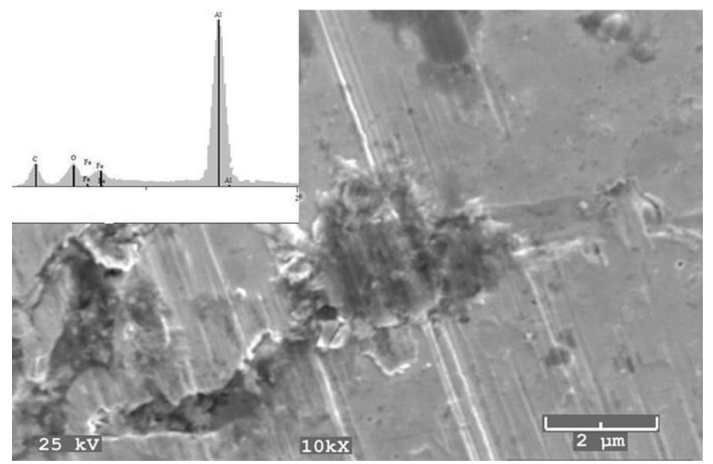

(c)

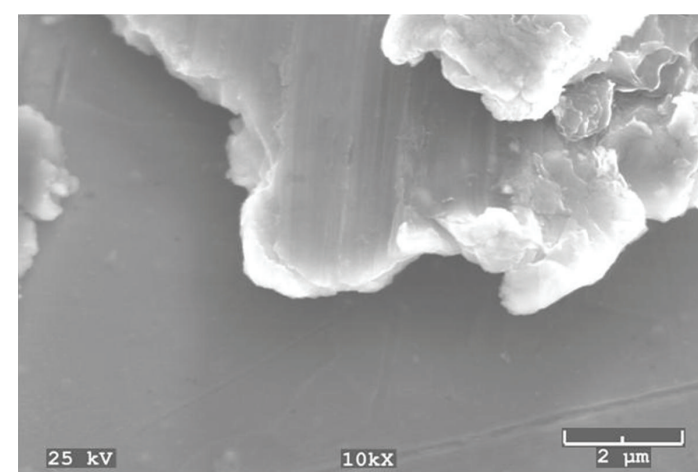

(b)

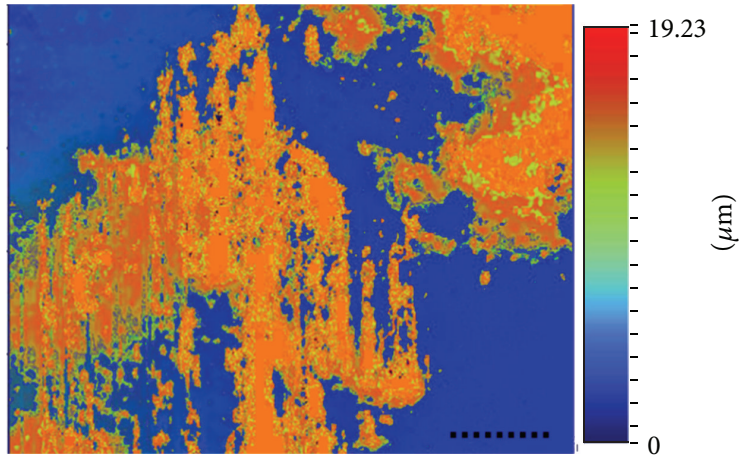

(d)

Figure 7: (a) An example of the metal transfer when $1100 \mathrm{Al}$ is slide on a unimplanted, unrolled ISF steel surface. Spectrum is taken from the debris marked with a dotted box. (b) High magnification image of the debris marked with a dotted box in Figure 5(a). (c) High magnification image of the debris marked with a solid box with EDS spectrum in Figure 5(a). (d) Optical profilometer scan of the metal transfer when 1100 $\mathrm{Al}$ is slide on the unimplanted, unrolled ISF steel surface. The dotted black line in the lower right-hand corner is a $50 \mu \mathrm{m}$ scale bar.

of the rider and using a Vickers hardness of $167 \mathrm{MPa}$ for $1100 \mathrm{Al}$ gave $2.9 \times 10^{-2}$. The size of the debris was also very large: Figure $7(\mathrm{~d})$ gives an example of an optical profilometer scan taken from this wear track. The protrusions from the surface were almost $19 \mu \mathrm{m}$ in some spots, but the majority of the debris height was in the $10-16 \mu \mathrm{m}$ range. The width of the debris was $1-25 \mu \mathrm{m}$. It is likely that in a multipass wear test protrusions of this size will continue to build up and result in larger friction coefficients due to the added ploughing component. Certainly if the ISF steel was a metalforming die material, protrusions of this size would damage the surface of the incoming material. In addition, the EDS analysis of the chemistry of the larger debris (Figure 7(b)) revealed no detectable iron, and the oxygen content was on par with an unworn $1100 \mathrm{Al}$ ball. However, the chemistry of the smaller debris (Figure 7(c)) contained Fe and elevated amounts of oxygen. A possible reason for this is that the smaller debris rolls more than the larger debris on the surface and as a result accumulates iron as the aluminum oxides. The chemistry indicates that the smaller debris was multi-particle, while the larger debris appeared to be single bodied with evidence of plastic tearing (see Figure 7(b)) on the surface. Repeated tumbling on a surface removes the wear particle's fractographic features from the wear event. For the larger debris, this is not the case as signs of tearing can be seen, which is in contrast with Figure 7 (c) where tears were not visible on the smaller debris and the debris looked compacted. The observed tears and plate-like morphology follow the delamination mechanism proposed by Suh et al. [29] in which shear forces transmit through a welded interface. The existence of large debris means that there was sufficient contact area to transmit the required force to cause this delamination in addition to appreciable shear stresses at the interface.

Nitrogen implantation had a measureable effect on metal transfer. Figure 8(a) shows an example of the metal transfer to the $2 \mathrm{e} 17$ ions $/ \mathrm{cm}^{2}, 100 \mathrm{kV} \mathrm{N}+$ implanted ISF steel plate. The Archard wear coefficient for the rider was $3.4 \times 10^{-4}$ giving two orders of magnitude reduction in $\mathrm{Al}$ wear compared to the unimplanted. Using optical profilometry, Figure 8(c), the debris was as high as $8 \mu \mathrm{m}$, which is still rather large and as a result could cause problems in tribosystems. The width of the debris was $1-8 \mu \mathrm{m}$. The chemistry of the debris measured by EDS also contained oxygen, iron, and nitrogen. In addition, the debris appeared to be multiparticle. The microgroove formation process likely incorporated the iron and nitrogen in the debris. Interestingly, EDS 


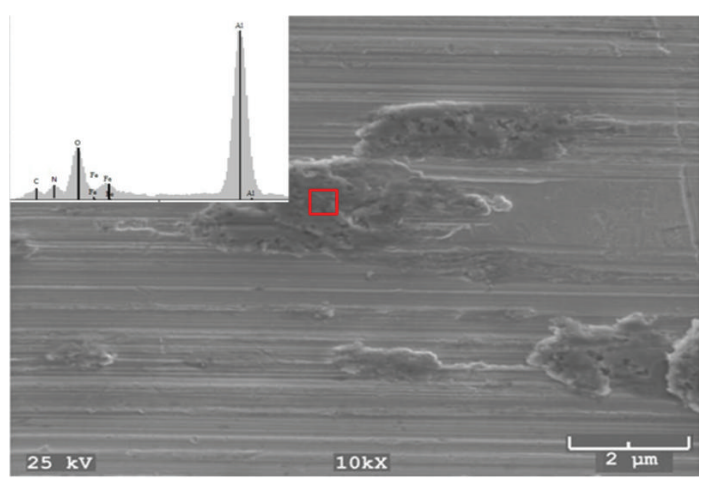

(a)

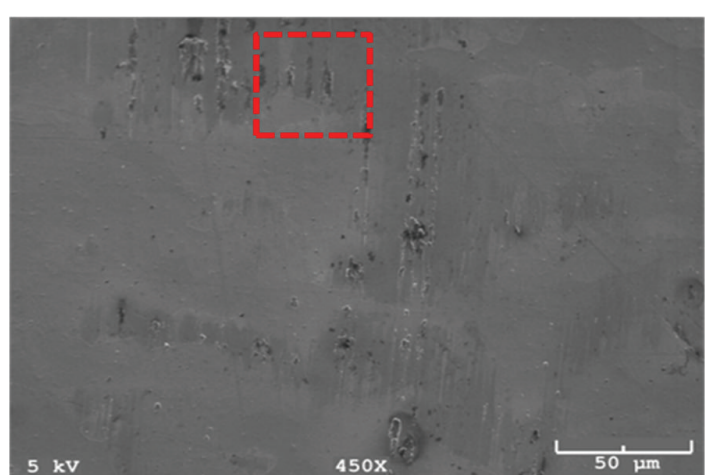

(b)

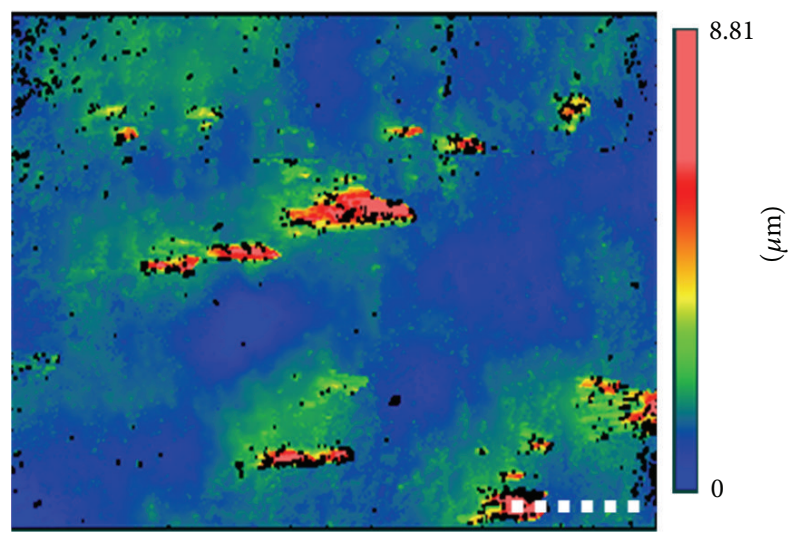

(c)

FIGURE 8: (a) SEM image of the debris transferred to the $2 \mathrm{e} 17 \mathrm{ions} / \mathrm{cm}^{2}, 100 \mathrm{kV} \mathrm{N}+$ implanted ISF steel plate. (b) High Magnification image of the debris within the dotted box. The $7 \mathrm{kV}$ EDS spectra of the debris are included. In addition, $\mathrm{Fe}, \mathrm{O}$, and $\mathrm{N}$ were detected on the scratched ISF steel surface (red box) at $7 \mathrm{kV}$. (c) Profilometry scan of the wear debris. The protrusions on the surface exceeded $8 \mu \mathrm{m}$ in some spots. The white dotted line is a $6 \mu \mathrm{m}$ scale bar.

$(5 \mathrm{kV})$ detected nitrogen inside the microgrooves indicating that the implanted layer was intact by some measure. Comparing the $5 \mathrm{kV} \mathrm{N}-\mathrm{K} \alpha$ signal of the $100 \mathrm{kV}$ implants outside of a microgroove and inside a microgroove gave $I_{\mathrm{N}-\mathrm{K} \alpha \text {, groove }} / I_{\mathrm{N}-\mathrm{K} \alpha \text {, surface }}=0.89$. Doing the same comparison for the $50 \mathrm{kV}$ implants gives $I_{\mathrm{N}-\mathrm{K} \alpha \text {, groove }} / I_{\mathrm{N}-\mathrm{K} \alpha \text {, surface }}=$ 0.21 . This means that the $50 \mathrm{kV}$ implants lost more nitrogen than the $100 \mathrm{kV}$ implants because of the microgroove formation, which is likely due to the higher concentration of the nitrogen with reference to the surface in the $50 \mathrm{kV}$ implantations $\left(2 \mathrm{el}\right.$ ions $/ \mathrm{cm}^{2}$ ). Compared to the debris in Figure $7(a)$, the fact that all of the debris appeared to be multiparticle means that the shear stresses were reduced to the point that large debris, too large to tumble on the surface, could not form in one wear event. The debris in Figure 8(a) reveals some evidence for small particle delamination, which was not destroyed by the tumbling process.

The relationship between the transferred $\mathrm{Al}$ area coverage on the ISF steel and the Al volume transfer is quadratic as Figure 9 indicates. The regression curve slope is the average Al transfer height, which increases with surface coverage. Adjacent to Figure 9 is a table showing the average debris height for each wear test as determined by the volumetric $\mathrm{Al}$ transfer divided by the $\mathrm{Al}$ covered area as described in the Methodology section. The average heights are 10.5-2.9 $\mu \mathrm{m}$. The measured debris heights in Figure 7(d) were $10-16 \mu \mathrm{m}$ and $4-8 \mu \mathrm{m}$ in Figure 8 (c). These measurements follow the regression curve trend of $\mathrm{Al}$ transfer height which increases with coverage. Note that the average debris height measured by profilometry is not exactly equivalent to the Al transferheight because debris also contains wear elements of ISF steel and can be ploughed into the surface.

Microgram scale measurements of the $\mathrm{Al}$ rider wear gave a relationship between wear and the hardness of the ISF steel $\left(H_{\text {hard }}\right)$ as achieved through cold rolling. The regression parameters $a$ and $b$ in (4) were adjusted to best fit the data. Figure 10 illustrates the regression analysis results for the unimplanted samples. The $R^{2}$ of the fit was 0.96 when $a$ and $b$ were $1.1 \times 10^{-5}$ and $4.7 \times 10^{-2}$, respectively. The average Archard wear coefficient $(b / W)$ was $2.6 \times 10^{-2}$. For the data points, the Archard coefficients based on (1) ranged from $2.0 \times 10^{-2}$ to $2.9 \times 10^{-2}$ depending on the amount of cold work-where cold rolling decreased its value. The error bars resulting from the repeatability tests (Figure 2) were included, which ends up being less than $2 \%$ of the 


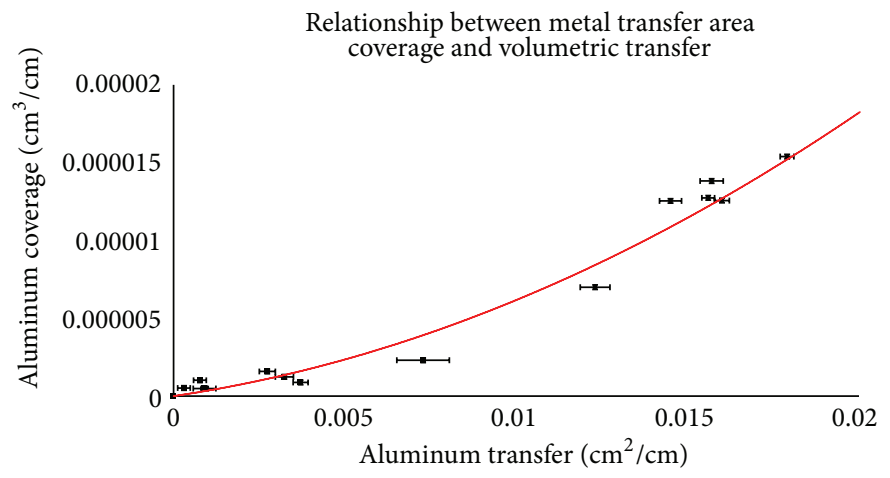

\begin{tabular}{lcc}
\hline \multicolumn{1}{c}{ Test } & $\begin{array}{c}\text { Ave debris } \\
\text { height } \\
(\mu \mathrm{m})\end{array}$ & $\begin{array}{c}\text { Ave debris } \\
\text { height error } \\
(\mu \mathrm{m})\end{array}$ \\
\hline ISF, 0\%, unimplanted & 10.5 & 0.65 \\
ISF, 7\%, unimplanted & 8.9 & 0.54 \\
ISF, 15\%, unimplanted & 8.9 & 0.54 \\
ISF, 30\%, unimplanted & 9.2 & 0.68 \\
ISF, 67\%, unimplanted & 8.8 & 0.55 \\
ISF, 100\%, unimplanted & 9.5 & 0.43 \\
ISF, 200\%, unimplanted & 9.6 & 0.54 \\
2e17 100 kV N & 2.4 & 0.73 \\
le17 100 kV N & 7.9 & 0.92 \\
5e16 100 kV N & 7 & 0.5 \\
2e17 50kV N & 5.1 & 0.86 \\
2e17 100 kV N, 100\% red & 3.5 & 1.08 \\
2e17 50 kV N, 100\% red & 2.9 & 0.78 \\
2e17 100 kV N, HT & 3.4 & 0.94 \\
2e17 100 kV N, 100\% red, HT 4.5 & 1.49 \\
\hline
\end{tabular}

FIGURE 9: Plot of volumetric metal transfer versus area covered by transferred wear debris.

reported values. The data indicates that the hardness of the harder material had a negligible effect on rider wear rates as the wear coefficient changed less than an order of magnitude.

Figure 11 reports the mass lost and mass transfer percentage for the unimplanted and implanted tests. Depending on the dose, some of the implanted samples had lower $\mathrm{Al}$ rider wear rates by almost two orders of magnitude; the (1) calculated wear coefficients for all the samples ranged from $3.4 \times 10^{-4}$ to $2.3 \times 10^{-3}$. Rider wear decreased with implantation dose: see $\mathbf{A}$ through $\mathbf{C}$ in Figure 11. In addition, fixing the dose and changing the accelerating voltage appeared to have a small effect on the rider wear (compare $\mathbf{A}$ and $\mathbf{D}$ in Figure 11) with the higher potential providing better wear properties. Rolling appeared to have no effect on the rider wear for the $2 \mathrm{e} 17$ ions $/ \mathrm{cm}^{2}$ at $100 \mathrm{kV}$ dose (compare $\mathbf{A}$ and $\mathbf{E}$ in Figure 11) and the $2 \mathrm{el} 7 \mathrm{ions} / \mathrm{cm}^{2}$ at $50 \mathrm{kV}$ dose (compare $\mathbf{D}$ and $\mathbf{F}$ in Figure 11). Unexpectedly, heat treating appeared to have no effect on rider wear (compare $\mathbf{A}$ and $\mathbf{G}$ and $\mathbf{E}$ and $\mathbf{H}$ in Figure 11). The metal transfer (red bars) decreased with implantation dose, which was the major controlling variable in reducing metal transfer for the implanted samples. Figure 11 also contains the percentage of metal transfer. Almost all of the rider wear became metal transfer for the unimplanted samples with metal transfer percentages above $90 \%$. In general, implantation reduced the metal transfer percentage by almost $40 \%$ for some conditions. However, the metal transfer \% measurements were within the same errorband for some of the samples. Based on the available data the metal transfer percentage decreased with implantation dose (compare $\mathbf{A}$ to $\mathbf{C}$ ) and energy (compare $\mathbf{A}$ to $\mathbf{D})$, but cold rolling had very little effect on this quantity.

The evaluation of friction traces helps to ascertain the nature of the interaction during sliding. The measured torque, rider offset, and load determined the coefficient of friction (COF). Figure 12(a) plots the COF for the different sets of tests. The COF for the unimplanted samples was 0.67$0.69 \pm 0.005$ and fell within the same margins of error. It appears that cold rolling has no detectable influence on the COF. Nitrogen implantation appeared to influence the COF; as the dose/energy increased, the COF decreased. At the lowest, the COF was $0.30 \pm 0.005$ for the $2 \mathrm{e} 17 \mathrm{ions} / \mathrm{cm}^{2}$ at $100 \mathrm{kV}$ implanted samples. In addition to having a lower friction coefficient the friction noise generated against the $\mathrm{N}+$ implanted plate was less. The noise levels for the unimplanted samples (20-25\%) were larger than the $\mathrm{N}+$ implanted samples (7-11\%). As the dose increased, the percentage of noise decreased. Note that the error bars in Figure 12(a) are determined by the data recording sensitivity of the tribometer software, which was $\pm 0.01 \mathrm{lbs} *$ inch. This gave a COF error of \pm 0.005 for a track diameter of $1.3^{\prime \prime}$ and a load of $3 \mathrm{lbs}$.

Table 1 gives the debris chemistries along with the near surface chemistries of the different samples. For proper statistics, five EDS spectrums from different debris were used for a given sample. Note that Table 1 also reports the standard deviation next to the average chemical composition for the five-sampled debris in a given sample. Only debris that appeared to be mixed were sampled; see Figures 7(c) and 8(a) for examples. The reported near-surface chemistry in Table 1 is a $300 \mathrm{~nm}$ average from the surface measured by the AES depth profiles. For the averaging, $1 \mathrm{~nm}$ spaced data points were used. As expected, the higher the nitrogen dose, the greater the average amount of nitrogen detected in the debris. The nitrogen-implanted samples had greater amounts of oxygen detected in the debris than the unimplanted. The amount of oxygen increased with nitrogen content in the debris; the Pearson correlation coefficient between those two variables was 0.47 based on the 75 debris chemistry samples (15 test conditions $\times 5$ debris samples). The critical Pearson correlation coefficient value based on this sample size is 0.3 for a $95 \%$ certainty, which indicates that there was a correlation between nitrogen and oxygen debris chemistries. 


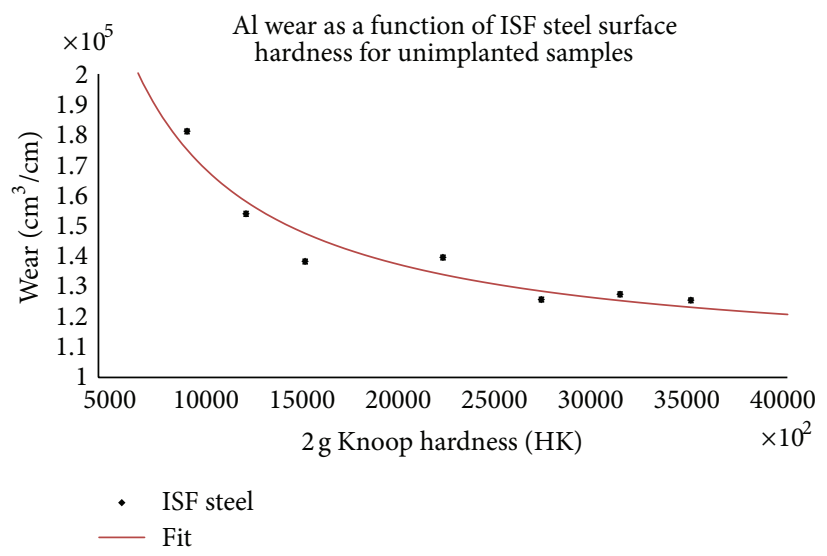

FIgURE 10: Metal transfer as a function of hardness for the unimplanted ISF Steel. The fit from (4) is included.

This indicates the nitrogen in the debris affected the tribooxidation that took place. Rolling had no measureable effect on the debris chemistry indicating that the fractured particles from the ISF steel going into the debris were less than the size of the implantation zone. This conclusion is based on the observation that the $2 \mathrm{~g}$ Knoop hardness measurements on samples $\mathbf{A}$ and $\mathbf{H}$ in Figure 12 were only 23 points apart (Sample $\mathbf{H}>\mathbf{A}$ ), but the $200 \mathrm{~g}$ Knoop hardness measurements were over 200 points apart (Sample $\mathbf{H}>\mathbf{A}$ ). It is expected that, if the ISF steel wear elements were larger than the implantation zone, cold rolling would affect the debris chemistry because there was a large difference in hardness values at a $200 \mathrm{~g}$ load. Unexpectedly, the energy of the implant affected the debris chemistry while keeping the implant dose constant. The lower energy implants produced debris with more nitrogen, but the oxygen content was within the margin of error of the $100 \mathrm{kV} 2 \mathrm{el}$ ions $/ \mathrm{cm}^{2}$ implants. The higher concentration of nitrogen near the surface may be the cause for the larger detected amounts of nitrogen, and this gives more evidence that the particles coming from the ISF steel are smaller than the implantation zone.

\section{Discussion}

The real contact area was defined by $W / H_{\text {eq }}$ in (4), but the $1 / H_{\text {hard }}$ term in (3) only slightly effected the wear rates. The difference in wear rates between the unrolled and $200 \%$ reduction samples was less than $1 / 5$ th of an order of magnitude. Practically, there are no differences in wear rates between the rolled ISF steel samples. This means that the real contact area can be defined by $W / H_{\text {soft }}$ as the hardness of the harder surface has little effect on the adhesive wear of the $\mathrm{Al}$ rider. This means that any reduction in wear from implantation is not related to differences in contact area generated by hardening. Kayaba et al. [30] proposed using a slip-line deformation model that the harder material asperities can yeild if an asperity tip angle is less than a critical value determined by $H_{\text {soft }} / H_{\text {hard }}$. These predictions have been qualitatively confimed by Fishkis [31] for steel/aluminum tests. Obviously, hard asperity yeilding will increase the real contact area; however this effect was not observed in terms of wear rate. It is likely that the chemical polishing smoothed out the surface such that the asperity angles were well-above the critical angle. It should be mentioned that the real contact area $\left(52816 \mu \mathrm{m}^{2}\right)$ exceeds the initial Hertzian apparent contact area $\left(6250 \mu \mathrm{m}^{2}\right)$, but not the final contact area as measured by the worn flat diameter $\left(148542 \mu \mathrm{m}^{2}\right)$. A more detailed Hertzian contact analysis revealed that the Von-Mises stresses in the Al ball exceeded the YS of the material, meaning that the initial Hertzian relationship does not apply and that the initial apparent contact area is much higher. A reasonable estimate for the initial contact area, which is under elastoplastic contact conditions, is obtained by finite element empirical modeling [32,33], which give apparent contact areas of 69234 and $66128 \mathrm{um}^{2}$, respectively. As expected, the real contact area as given by $W / H_{\text {soft }}$ is lower than modeled apparent contact area by about $22 \%$.

These sets of experiments are unique in that the ion implantation was not originally meant to improve the wear resistance of ISF steel, but to reduce the wear of the 1100 Al rider. In addition, volumetric wear data for single pass experiments to our knowledge have not been published. As a result, finding comparable data within the current context of experiments is difficult. The most relevent set of published, qualitative metal transfer data is provided by Antler [34] where the volumetric wear for a series of pure-metal combinations was studied under multipass wear tests. For pure $\mathrm{Al}$ on pure $\mathrm{Al}$ the rider volumetric wear rate was $1.5 \times 10^{-6} \mathrm{~cm}^{3} / \mathrm{cm}$. Comparing our value for ISF steel with $1100 \mathrm{Al}\left(1.7 \times 10^{-5} \mathrm{~cm}^{3} / \mathrm{cm}\right)$ the much higher value is likely due to run-in effects from the chemically polished ISF steel surface. Remember that while the Al rider is being run-in during wear testing the rider is continuously encountering a fresh, unworn ISF steel surface. The other difference is likely due to preparation methods; Anlter used mechanical grinding for sample preparation while we used chemical polishing. The real contact areas were likely larger due to the lower RMS values associated with chemical polishing. Figure 13 demonstrates that $\mathrm{N}+$ 
TABLE 1: Debris and near-surface chemistries for the samples used in this test.

\begin{tabular}{|c|c|c|c|c|c|c|}
\hline \multirow{2}{*}{ Sample } & \multicolumn{3}{|c|}{ Debris chemistry } & \multicolumn{3}{|c|}{ Near-surface chemistry } \\
\hline & Oxygen $($ At $\%)$ & Carbon $($ At\%) & Nitrogen $($ At $\%)$ & Oxygen (At\%) & Carbon $($ At $\%)$ & Nitrogen $($ At $\%)$ \\
\hline Unimplanted & $7.2,1.5$ & $2.1,1.3$ & NA & 0.3 & $<0.1$ & 0.0 \\
\hline Unimplanted, $7 \%$ reduction & $8.1,1.3$ & $2.4,0.5$ & NA & 0.4 & $<0.1$ & 0.0 \\
\hline Unimplanted, $15 \%$ reduction & $6.3,1.7$ & $2.9,0.9$ & NA & 0.2 & $<0.1$ & 0.0 \\
\hline Unimplanted, $30 \%$ reduction & $6.4,1.4$ & $3.0,0.8$ & NA & 0.1 & $<0.1$ & 0.0 \\
\hline Unimplanted, $67 \%$ reduction & $6.2,1.9$ & $2.5,0.5$ & $\mathrm{NA}$ & 0.2 & $<0.1$ & 0.0 \\
\hline Unimplanted, $100 \%$ reduction & $7.1,1.9$ & $2.7,1.1$ & NA & 0.3 & $<0.1$ & 0.0 \\
\hline Unimplanted, $200 \%$ reduction & $6.9,1.5$ & $2.2,1.5$ & NA & 0.1 & $<0.1$ & 0.0 \\
\hline $\mathrm{N}+$ implanted, $5 \mathrm{e} 16$ ions $/ \mathrm{cm}^{2}$ at $100 \mathrm{kV}$ & $11.7,1.4$ & $2.4,1.1$ & $2.1,0.5$ & 1.4 & $<0.1$ & 3.8 \\
\hline $\mathrm{N}+$ implanted, $1 \mathrm{e} 17 \mathrm{ions} / \mathrm{cm}^{2}$ at $100 \mathrm{kV}$ & $12.5,1.1$ & $2.1,1.7$ & $4.0,0.8$ & 2.2 & $<0.1$ & 7.1 \\
\hline $\mathrm{N}+$ implanted, $2 \mathrm{el} 7 \mathrm{ions} / \mathrm{cm}^{2}$ at $100 \mathrm{kV}$ & $16.4,1.6$ & $2.9,1.2$ & $6.5,1.1$ & 3.3 & $<0.1$ & 12.5 \\
\hline $\mathrm{N}+$ implanted, $2 \mathrm{e} 17$ ions $/ \mathrm{cm}^{2}$ at $50 \mathrm{kV}$ & $15.1,1.8$ & $2.2,0.8$ & $9.9,0.7$ & 2.0 & $<0.1$ & 10.1 \\
\hline $\begin{array}{l}\mathrm{N}+\text { implanted, } 2 \mathrm{e} 17 \text { ions } / \mathrm{cm}^{2} \text { at } 100 \mathrm{kV} \text {, } \\
100 \% \text { reduction }\end{array}$ & $16.6,1.2$ & $2.2,1.4$ & $6.3,1.7$ & 3.1 & $<0.1$ & 12.7 \\
\hline $\begin{array}{l}\mathrm{N}+\text { implanted, } 2 \mathrm{e} 17 \text { ions } / \mathrm{cm}^{2} \text { at } 50 \mathrm{kV} \text {, } \\
100 \% \text { reduction }\end{array}$ & $16.2,1.5$ & $2.7,1.2$ & $9.1,0.5$ & 2.0 & $<0.1$ & 10.3 \\
\hline $\begin{array}{l}\mathrm{N}+\text { implanted, } 2 \mathrm{e} 17 \text { ions } / \mathrm{cm}^{2} \text { at } 100 \mathrm{kV} \\
\text { heat treated }\end{array}$ & $16.9,1.3$ & $2.1,1.6$ & $3.9,1.1$ & 3.9 & $<0.1$ & 12.1 \\
\hline $\begin{array}{l}\mathrm{N}+\text { implanted, } 2 \mathrm{e} 17 \text { ions } / \mathrm{cm}^{2} \text { at } 100 \mathrm{kV} \text {, } \\
100 \% \text { reduction, heat treated }\end{array}$ & $16.1,2.2$ & $2.6,1.7$ & $7.0,1.3$ & 4.0 & $<0.1$ & 12.2 \\
\hline
\end{tabular}

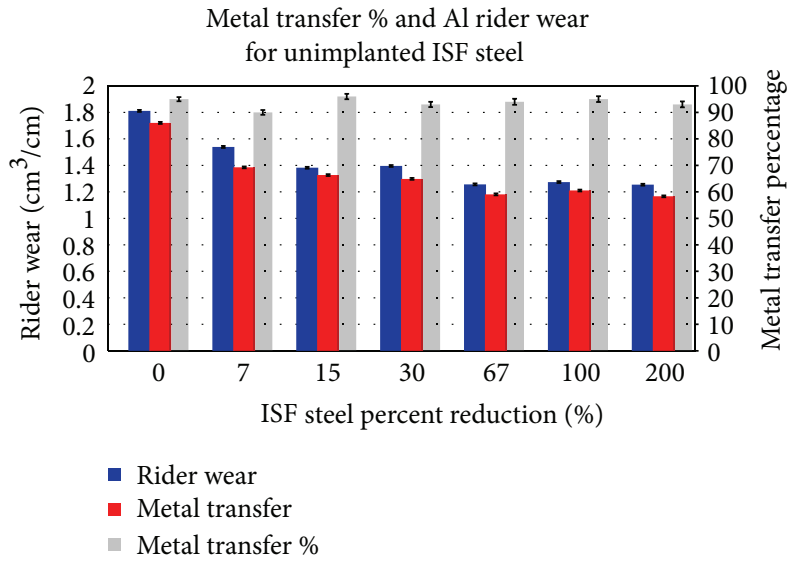

(a)

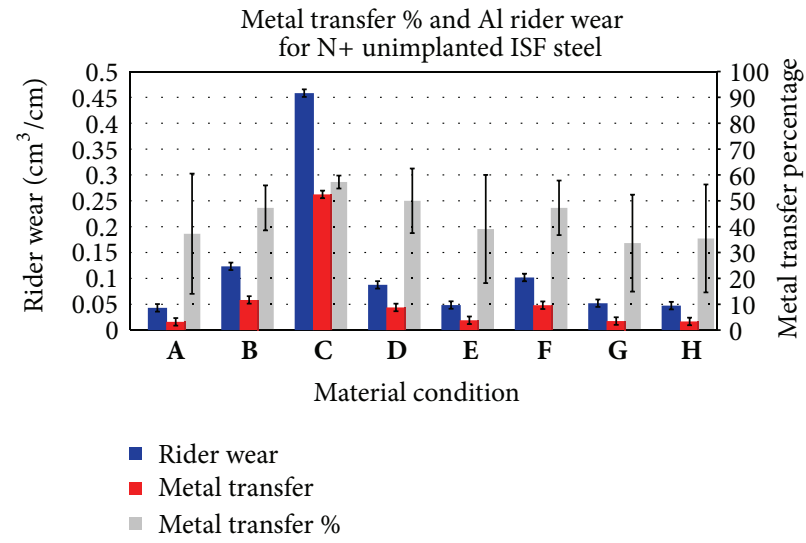

(b)

FIGURE 11: Rider wear and metal transfer percentage for the various tested conditions. The label references for the N+ implanted labels are provided at the bottom. Note that the rider wear for the N-implanted samples (b) were scaled by a factor of $10 . \mathbf{A}=2 \mathrm{el} 7 \mathrm{ions} / \mathrm{cm}^{2}$ at $100 \mathrm{kV}, \mathbf{B}$ $=1 \mathrm{e} 17 \mathrm{ions} / \mathrm{cm}^{2}$ at $100 \mathrm{kV}, \mathbf{C}=5 \mathrm{e} 16 \mathrm{ions} / \mathrm{cm}^{2}$ at $100 \mathrm{kV}, \mathbf{D}=2 \mathrm{e} 17 \mathrm{ions} / \mathrm{cm}^{2}$ at $50 \mathrm{kV}, \mathbf{E}=2 \mathrm{e} 17 \mathrm{ions} / \mathrm{cm}^{2}$ at $100 \mathrm{kV}$ at $100 \% \mathrm{red}, \mathbf{F}=2 \mathrm{e} 17 \mathrm{ions} / \mathrm{cm}^{2}$ at $50 \mathrm{kV} ; 100 \%$ red, $\mathbf{G}=2 \mathrm{e} 17$ ions $/ \mathrm{cm}^{2} ; 100 \mathrm{kV}$; heat treat, and $\mathbf{H}=2 \mathrm{e} 17$ ions $/ \mathrm{cm}^{2}$ at $100 \mathrm{kV} ; 100 \%$ red; heat treat.

ion implantation reduced the amount of rider wear and the amount of metal transfer to the plate, but the structure of the nitride as altered by heat treating the implanted zone appeared to have no effect on the rider wear. The improvement from implantation in the rider wear was at most two orders of magnitude for the $2 \mathrm{e} 17 \mathrm{ions} / \mathrm{cm}^{2}$ at $100 \mathrm{kV}$ implantations (including rolled and heat treated). The $2 \mathrm{e} 17 \mathrm{ions} / \mathrm{cm}^{2}$ at $100 \mathrm{kV}$ implantation wear coeficients were in the $3 \times 10^{-4}-7 \times 10^{-4}$ range, which is also in the moderate wear regime.
The rider wear mechanisms need to be discussed prior to evaluating the benefits of nitrogen implantation. The surface roughnesses of the evaluated surfaces were $0.010-0.005 \mu \mathrm{m}$, and by determining the number of apex points in a given area through the MetroPro software the maximum abrasive wear can be deduced. The estimated maximum abrasive wear rates were from $8 \times 10^{-7}$ to $1 \times 10^{-6} \mathrm{~cm}^{3} / \mathrm{cm}$, which is almost two orders of magnitude less than the measured wear rates for the unimplanted samples. This means that abrasive wear was initially negligiable and adhesive wear via 
Average coefficient of friction during Unimplanted sample tests
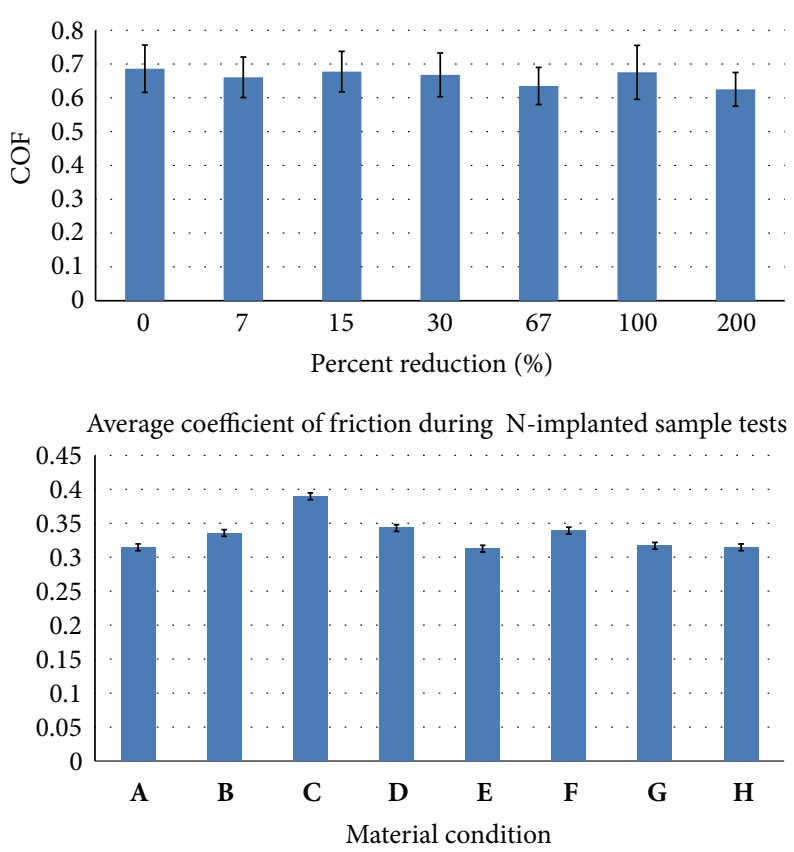

(a)

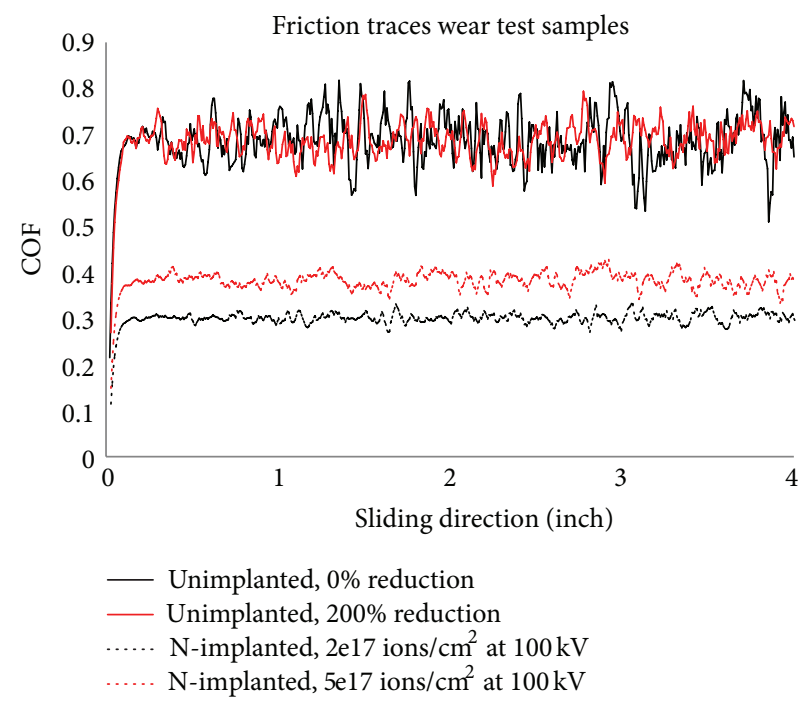

(b)

Figure 12: (a) Average friction coefficients of tested samples: unimplanted (Top) and N-implanted (Bottom). A = 2el7 ions $/ \mathrm{cm}^{2}$ at $100 \mathrm{kV}, \mathbf{B}$ $=1 \mathrm{e} 17 \mathrm{ions} / \mathrm{cm}^{2}$ at $100 \mathrm{kV}, \mathbf{C}=5 \mathrm{e} 16$ ions $/ \mathrm{cm}^{2}$ at $100 \mathrm{kV}, \mathbf{D}=2 \mathrm{e} 17 \mathrm{ions} / \mathrm{cm}^{2}$ at $50 \mathrm{kV}, \mathbf{E}=2 \mathrm{el} 17 \mathrm{ions} / \mathrm{cm}^{2}$ at $100 \mathrm{kV}$ at $100 \% \mathrm{Red}, \mathbf{F}=2 \mathrm{el}$ ions $/ \mathrm{cm}^{2}$ at $50 \mathrm{kV} ; 100 \%$ red, $\mathbf{G}=2 \mathrm{el} 7$ ions $/ \mathrm{cm}^{2} ; 100 \mathrm{kV}$; heat treat, and $\mathbf{H}=2 \mathrm{e} 17$ ions $/ \mathrm{cm}^{2}$ at $100 \mathrm{kV} ; 100 \%$ red; heat treat. (b) Example friction traces for different samples.

delamination dominated. It is expected that if abrasive wear was a factor in these studies, cold rolling the ISF steel should have raised the wear rate of the $\mathrm{Al}$ rider because harder asperities will blunt less as they penetrate into the Al surface. The fact that the unimplanted samples displayed friction traces with relatively large noise levels at $20-25 \%$ indicates that a two-body stick-slip mechanism $[35,36]$ existed. This is also evidence of adhesive wear occuring because sufficient adhesive forces are needed to create the stick-slip condition. Stick-slip conditions arise when asperity junctions weld, and the junctions grow. The sticking condition ends, and slip begins with the formation of a wear element. The junction could also separate without wear element formation. The COF noise was reduced to $5-10 \%$ in the implanted samples. Implantation also had the effect of reducing the COF by 0.25-0.35 depending on the dose. According to Table 1, the near-surface nitrogen chemistry negatively correlated with decreases in both the friction coefficient and noise, which indicated that the nitrogen chemistry disrupted the stickslip process by reducing the adhesive forces. Using Tabors junction growth formula, (5), given the COF and noise, the average shear strength of the interface can be determined. Equation (5) uses the shear yield strength of Al-3.26 ksi. The $2 \mathrm{e} 17 \mathrm{ions} / \mathrm{cm}^{2}$ at $100 \mathrm{kV}$ implantation had an average interfacial shear strength of $0.45 \mathrm{ksi}$ while the unimplanted sample was $0.94 \mathrm{ksi}$. Using Density Functional Theory (DFT) calculations $(\{100\} \mathrm{Al} \mid\{\{100\} \mathrm{Fe}$ interface calculations were performed using density function theory with the VASP software package. The plane augmented wave method was used for the atomic potentials. The exchange-correlation term was handled using the generalized gradient approximation. The calculations were converged to within $0.01 \mathrm{eV}$ with respect to plane wave basis set size, k-point mesh density, vacuum gap, and layer size.) of the $\mathrm{Fe} \mid \mathrm{Al}\{100\}$ interface along with the real contact area $\left(W / H_{\text {soft }}\right)$ provides an upper limit in the estimation of the adhesion strength. DFT calculations indicated that the interfacial cleavage energy was rougly $50 \%$ higher than bulk aluminum. Assuming that the same relationship approximately holds for the shear strength, an estimate of the shear strength of the $\mathrm{Fe} \mid \mathrm{Al}$ interface is $4.89 \mathrm{ksi}$. This indicates that interfacial films played a role in reducing the interfacial shear strength for all tests during the sticking phase. The implanted samples had a lower interfacial shear strength by almost $0.49 \mathrm{ksi}$ than the unimplanted indicating that the chemistry played a role whether it be the oxide film, the implanted nitrogen, or both.

Implanting nitrogen reduced the metal transfer percentage relative to the unimplanted condition. Comparing Figure 11 with Table 1 indicates that the metal transfer percentage decreased with average debris nitrogen and oxygen content. The reasons for the reduction in metal transfer percentage is likely due to the presence of nonmetallic, abrasive particles that promote the removal of wear debris from the contact region [37]. The transfer metal debris chemisty was mixed 


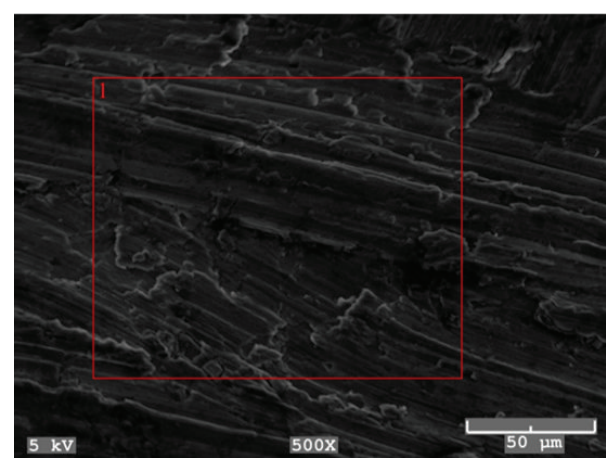

(a)

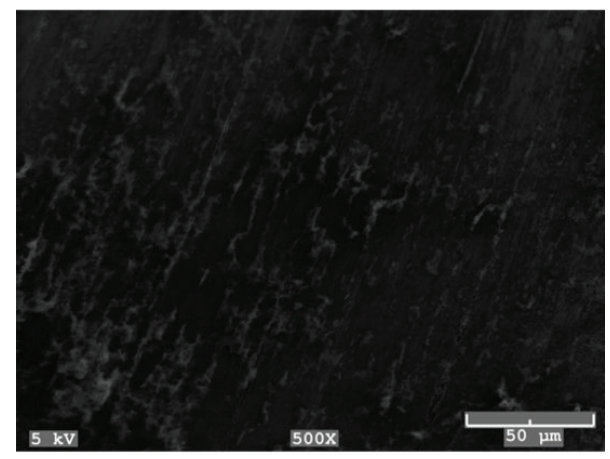

(b)

FIGURE 13: (a) Rider wear surface tested against the unimplanted ISF Steel surface. (b) Rider wear surface tested against the $2 \mathrm{el} 7 \mathrm{ions} / \mathrm{cm}^{2}$ at $100 \mathrm{kV}$ nitrogen implantation condition.

( $\mathrm{Fe}, \mathrm{Al}, \mathrm{O}$, and $\mathrm{N}$ ) with the exception of the debris that included larger wear elements (see Figure 7(b)). TEM studies by Rigney et al. [38] indicated that debris transfer layers are multiparticle and multielement, which results from the mobility of the debris. Mechanically mixed and oxidized wear debris can act as a beneficial tribolayer [39-41]. According to the Mutual Material Transfer model, when a wear element forms on an opposing surface, it creates a protrusion that acts like an asperity. There is a certain probability that another wear element will form on top of previously generated wear element. In this manner, the debris will build up until it reaches a critical size in which the obstruction forces between the adhered debris and the sliding surfaces overcome the adhesion forces between the debris and the surface it is attached to resulting in the expelling of the debris from the wear track. If the debris is composed of less adherent particles such as oxides, and nitrides the adhesion force between the debris and its attached surface is reduced, which should reduce the critical-size of the debris. Figure 9 is indirect evidence to support the last statement because the reduction in wear rate was due to a reduction in adhesion from the presence of oxides and nitrides in the surface layer. Back transfer to the $\mathrm{Al}$ pin was also reduced by implantation. Evidence of $\mathrm{Al}$ back transfer to the rider is demonstated in Figure 13(a) where large $\mathrm{Al}$ particles can be seen sticking to the Al surface as opposed to the rider that slids on the $\mathrm{N}$-implanted surface (Figure 13(b)), which had no evidence of back transfer. EDS chemistries taken from the rider wear surfaces indicated the presence of ISF steel transfer elements.

The oxides that formed are due to tribo-oxidation [42]. There also is evidence that nitrogen implantation enhances the benefits of tribo-oxidation during high cycle wear tests $[43,44]$. The amount of oxygen in the debris was positively correlated with the nitrogen debris chemistry as the 0.47 Pearson correlation coeficient indicates. This means that nitrogen implantation had an effect on tribooxidation. Due to the fact that native oxide films are self-limiting, most of the oxidation likely occurred during the mechanical mixing of the wear elements because of the higher temperatures associated with cold working the particles. There is sufficient evidence $[45,46]$ that $\mathrm{N}$ implantation effects the low-temperature oxidative properties of iron. All exposed transition metal surfaces have native oxide films on them. As mentioned above implantation has an effect on the tribooxidation of the debris. Figure 14 contains depth profiles of oxygen for the nitrogen implantations after 15 days of implantation with a reference unimplanted surface. The depth of the native oxide layer increased with implantation dose and energy. At the heaviest dose the film increased by as much as a factor of 3.5 with reference to the unimplanted sample. XPS (Fe 2p 3/2) surveys (unimplanted and $2 \mathrm{e} 17$ ions $/ \mathrm{cm}^{2}$ at $100 \mathrm{kV}$ ) after $400 \mathrm{~s}$ of sputtering to remove the surface carbon are also included. Implantation had the effect of increasing the amount of the $\mathrm{Fe}-\mathrm{O}$ (III)/Fe-O(II) peak ratio relative to the unimplanted sample presumably due to the larger oxygen concentrations. The lattice defects created by implantation likely enhanced the migration rate of the changed species by the increased vaccancy count. The thicker oxidation layer present probably also helped in reducing the adhesion, which in turn reduced the size of the wear particles through delamination and the level of friction from junction growth. In addition, the larger oxide film likely helped incorporate less adherent ISF steel wear elements into the debris.

The quadratic relationship between the area covered and the volumetric transfer for a transferred material has not been established in the literature. In fact, the factors that affect debris size are usually related to the wear rate. Factors such as test load [47], roughness of the harder surface [48], and test speed [49] are related to wear rate. In some studies [50], debris size is related directly to wear rate. In this study, the load, speed, and surface roughness values are held constant. Thus, debris size changes are due to the factors that directly affect metal transfer. According to the Mutual Material Transfer mechanism debris builds up until it reaches a critical size. At that point, the obstruction forces overcome the debris surface adhesive force and cause the particle to be removed from the wear surface. Ploughing into the ISF steel should provide additional mechanical keying and allow larger size debris to form. Hence, according to the Mutual Material Transfer model only two factors should influence debris size: wear element size distribution and the adhesion of the debris to the surface. The Figure 10 provides a useful tool when evaluating metal transfer when the mass transferred is below the sensitivity of the microbalance. 
AES depth profiles of oxygen versus different implantation conditions
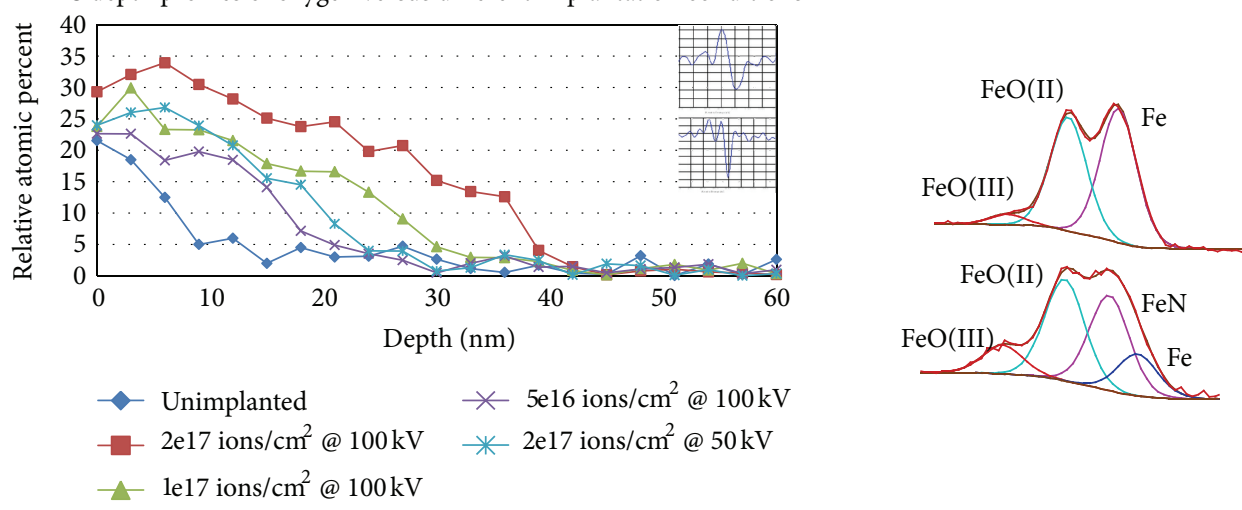

FIGURE 14: AES depth profile of oxygen for different implantation conditions. To the right are XPS (Mg K $\alpha$ X-rays) surveys of the Fe 2p 3/2 photoelectron peaks after $400 \mathrm{~s}$ of sputtering to remove the surface carbon.

\section{Conclusions}

(i) Examining the metal-transfer/rider-wear data for the cold-rolled ISF steel shows that the tribological processes are not significantly impacted by hardness (less than $1 / 5$ th an order of magnitude), and the $W / H_{\text {soft }}$ expression can be even when the hardness of the harder surface is changing.

(ii) Nitrogen implantation enhanced the native oxide film thickness by a factor of three two weeks after implantation. The enhancement is due to the knock on damage caused by implantation.

(iii) Ion implantation had the effect of reducing the $\mathrm{Al}$ rider wear by two orders of magnitude. The reduction in the Al rider wear was attributed to the near-surface nitrogen chemistry and the native oxide layer formed after implantation. Postimplantation heat treating caused $\varepsilon-\mathrm{Fe}_{3} \mathrm{~N}$ to decompose to $\gamma^{\prime}-\mathrm{Fe}_{4} \mathrm{~N}$, but this had no impact on the $\mathrm{Al}$ rider wear, which indicates that wear reduction was due to chemistry of the ISF steel near surface and not structure.

(iv) Implantation of nitrogen enhanced the debris tribooxidation process; the oxygen content in the debris showed a strong correlation with nitrogen nearsurface chemistry. Due to the enhanced oxygen and nitrogen debris chemistry the fraction of $\mathrm{Al}$ debris ending up as metal transfer to the ISF steel surface was reduced.

(v) The noisy friction coefficient indicated that stick-slip wear mechanism was responsible for friction generation. Nitrogen implantation reduced both the friction coefficient and the friction noise. Calculations based on the Tabors junction growth formula indicate that nitrogen implantation reduced the adhesive strength of the interface with reference to the unimplanted surface.

\section{Acknowledgments}

Authors would like to thank Arcelor Mittal for supplying the ISF steel, the staff at the University of Michigan Ion Beam Laboratory and University of Albany Ion Beam Laboratory for their help in getting the implantations done, and the University of Connecticut's Institute of Materials Science and Deringer-Ney for instrumentation time. One of the authors currently has no financial ties to Arcelor Mittal or DeringerNey. Funding for this study was provided by the University of Connecticut's Institute of Materials Science.

\section{References}

[1] H. Wallin, An investigation of friction graphs ranking ability regarding the galling phenomenon in dry SOFS contact [Thesis], Faculty of Technology and Science Department of Material Science Karlstad University.

[2] J. T. Burwell and C. D. Strang, "Metallic Wear," Proceedings of the Royal Society of London A, vol. 212, Mathematical and Physical Sciences, no. 1111, pp. 470-477, 1952.

[3] ASTM G98-02, 2009, Standard test method for galling resistance of materials.

[4] T. Sasada and S. Norose, "Formation and growth of wear particles through mutual material transfer," in Proceedings of the JSLE-ASLE International Lubrication Conference, pp. 82-91, American Elsevier Publishing, New York, NY, USA, 1976.

[5] A. Hase and H. Mishina, "Wear elements generated in the elementary process of wear," Tribology International, vol. 42, no. 11-12, pp. 1684-1690, 2009.

[6] A. Gåård, P. Krakhmalev, and J. Bergström, "Wear mechanisms in galling: cold work tool materials sliding against high-strength carbon steel sheets," Tribology Letters, vol. 33, no. 1, pp. 45-53, 2009.

[7] S. R. Hummel and B. Partlow, "Comparison of threshold galling results from two testing methods," Tribology International, vol. 37, no. 4, pp. 291-295, 2004.

[8] S. R. Hummel, "Development of a galling resistance test method with a uniform stress distribution," Tribology International, vol. 41, no. 3, pp. 175-180, 2008. 
[9] U. Wiklund and I. M. Hutchings, "Investigation of surface treatments for galling protection of titanium alloys," Wear, vol. 251, no. 1-12, pp. 1034-1041, 2001.

[10] S. R. Hummel, "An application of frictional criteria for determining galling thresholds in line contact tests," Tribology International, vol. 35, no. 12, pp. 801-807, 2002.

[11] I. L. Singer, "Surface analysis, ion implantation and tribological processes affecting steels," Applied Surface Science, vol. 18, no. 1-2, pp. 28-62, 1984.

[12] J. K. Hirvonen, C. A. Carosella, R. A. Kant, I. Singer, R. Vardiman, and B. B. Rath, "Improvement of metal properties by ion implantation," Thin Solid Films, vol. 63, no. 1, pp. 5-10, 1979.

[13] T. Fujihana, Y. Okabe, and M. Iwaki, "Effects of implantation temperature on the hardness of iron nitrides formed with high nitrogen dose," Nuclear Instruments and Methods in Physics Research Section B, vol. 39, no. 1-4, pp. 548-551, 1989.

[14] T. Fujihana, A. Sekiguchi, Y. Okabe, K. Takahashi, and M. Iwaki, "Effects of room temperature carbon, nitrogen and oxygen implantation on the surface hardening and corrosion protection of iron," Surface and Coatings Technology, vol. 51, no. 1-3, pp. 1923, 1992.

[15] H. Dimigen, K. Kobs, R. Leutenecker, H. Ryssel, and P. Eichinger, "Wear resistance of nitrogen-implanted steels," Materials Science and Engineering, vol. 69, no. 1, pp. 181-190, 1985.

[16] A. A. Youssef, P. Budzynski, J. Filiks, A. P. Kobzev, and J. Sielanko, "Improvement of wear and hardness of steel by nitrogen implantation," Vacuum, vol. 77, no. 1, pp. 37-45, 2004.

[17] W. C. Oliver, R. Hutchings, and J. B. Pethica, "The wear behavior of nitrogen-implanted metals," Metallurgical and Materials Transactions A, vol. 15, no. 12, pp. 2221-2229, 1984.

[18] P. Tarkowski, P. Budzynski, and W. Kasietczuk, "Adhesive character of wear processes in nitrogen-implanted iron," Vacuum, vol. 78, no. 2-4, pp. 679-683, 2005.

[19] R. Wei, P. J. Wilbur, W. S. Sampath, D. L. Williamson, and J. L. Wang, "Effects of Ion implantation conditions on the tribology of ferrous surfaces," Tribology, vol. 113, pp. 166-173, 1991.

[20] I. M. Feng, "Metal transfer and wear," Journal of Applied Physics, vol. 23, no. 9, pp. 1011-1019, 1952.

[21] D. A. Rigney, "The roles of hardness in the sliding behavior of materials," Wear, vol. 175, no. 1-2, pp. 63-69, 1994.

[22] C. C. Viáfara and A. Sinatora, "Influence of hardness of the harder body on wear regime transition in a sliding pair of steels," Wear, vol. 267, no. 1-4, pp. 425-432, 2009.

[23] D. W. Borland and S. Bian, "Unlubricated sliding wear of steels: towards an alternative wear equation," Wear, vol. 209, no. 1-2, pp. 171-178, 1997.

[24] D. Tabor, "Junction growth in metallic friction: the role of combined stresses and surface contamination," Proceedings of the Royal Society of London A, vol. 251, no. 1266, pp. 378-393, 1959.

[25] D. Rafaja, "X-ray diffraction and X-ray reflectivity applied to the investigation of thin films," Advances in Solid State Physics, vol. 41, pp. 275-286, 2001.

[26] M. Kopcewicz and J. Jagielski, "Phase transformations in nitrogen-implanted $\alpha$-iron," Journal of Applied Physics, vol. 71, no. 9, pp. 4217-4226, 1992.

[27] A. A. Youssef, P. Budzynski, J. Filiks, A. P. Kobzev, and J. Sielanko, "Improvement of wear and hardness of steel by nitrogen implantation,” Vacuum, vol. 77, no. 1, pp. 37-45, 2004.
[28] G. Bhargava, I. Gouzman, C. M. Chun, T. A. Ramanarayanan, and S. L. Bernasek, "Characterization of the "native" surface thin film on pure polycrystalline iron: a high resolution XPS and TEM study," Applied Surface Science, vol. 253, no. 9, pp. 43224329, 2007.

[29] N. P. Suh, N. Saka, and S. Jahanmir, "Implications of the delamination theory on wear minimization," Wear, vol. 44, no. 1, pp. 127-134, 1977.

[30] T. Kayaba, K. Kato, and K. Hokkirigawa, “Theoretical analysis of the plastic yielding of a hard asperity sliding on a soft flat surface," Wear, vol. 87, no. 2, pp. 151-161, 1983.

[31] M. Fishkis, "Metal transfer in the sliding process," Wear, vol. 127, no. 1, pp. 101-110, 1988.

[32] R. L. Jackson and I. Green, "A finite element study of elastoplastic hemispherical contact against a rigid flat," Journal of Tribology, vol. 127, no. 2, pp. 343-354, 2005.

[33] L. Kogut and I. Etsion, "A finite element based elastic-plastic model for the contact of rough surfaces," Tribology Transactions, vol. 46, no. 3, pp. 383-390, 2003.

[34] M. Antler, "Processes of metal transfer and wear," Wear, vol. 7, no. 2, pp. 181-203, 1964.

[35] M. Antler, "Wear, friction, and electrical noise phenomena in severe sliding systems," ASLE Transactions, vol. 5, no. 2, pp. 297307, 1962

[36] A. D. Berman, W. A. Ducker, and J. N. Israelachvili, "Origin and characterization of different stick-slip friction mechanisms," Langmuir, vol. 12, no. 19, pp. 4559-4562, 1996.

[37] T. Sasada, M. Oike, and N. Emori, "The effect of abrasive grain size on the transition between abrasive and adhesive wear," Wear, vol. 97, no. 3, pp. 291-302, 1984.

[38] D. A. Rigney, L. H. Chen, M. G. S. Naylor, and A. R. Rosenfield, "Wear processes in sliding systems," Wear, vol. 100, no. 1-3, pp. 195-219, 1984.

[39] D. A. Rigney, "Sliding wear of metals," Annual Review of Materials Science, vol. 18, pp. 141-163, 1988.

[40] J. Jiang, F. H. Stott, and M. M. Stack, "A mathematical model for sliding wear of metals at elevated temperatures," Wear, vol. 181-183, no. 1, pp. 20-31, 1995.

[41] R. L. Deuis, C. Subramanian, and J. M. Yellup, "Dry sliding wear of aluminium composites-a review," Composites Science and Technology, vol. 57, no. 4, pp. 415-435, 1997.

[42] I. M. Hutchings, Tribology: Friction and Wear of Engineering Materials, Arnold, London, UK, 1992.

[43] H. J. Kim, A. Emge, S. Karthikeyan, and D. A. Rigney, "Effects of tribooxidation on sliding behavior of aluminum," Wear, vol. 259, no. 1-6, pp. 501-505, 2005.

[44] P. Budzynski, A. A. Youssef, Z. Surowiec, and R. Paluch, "Nitrogen ion implantation for improvement of the mechanical surface properties of aluminum," Vacuum, vol. 81, no. 10, pp. 1154-1158, 2007.

[45] A. Galerie, M. Caillet, and M. Pons, "Oxidation of ionimplanted metals," Materials Science and Engineering, vol. 69, no. 2, pp. 329-340, 1985.

[46] G. Dearnaley, "The alteration of oxidation and related properties of metals by ion implantation," Nuclear Instruments and Methods, vol. 182-183, no. 2, pp. 899-914, 1981.

[47] K. M. Jasim and E. S. Dwarakadasa, "SEM studies of wear debris in Al-Si alloys," Journal of Materials Science Letters, vol. 8, no. 11, pp. 1285-1287, 1989. 
[48] H. J. Cho, W. J. Wei, H. C. Kao, and C. K. Cheng, "Wear behavior of UHMWPE sliding on artificial hip arthroplasty materials," Materials Chemistry and Physics, vol. 88, no. 1, pp. 9-16, 2004.

[49] K. M. Jasim and E. S. Dwarakadasa, "Effect of sliding speed on adhesive wear of binary Al-Si alloys," Journal of Materials Science Letters, vol. 12, no. 9, pp. 650-653, 1993.

[50] U. Beerschwinger, T. Albrecht, D. Mathieson, R. L. Reuben, S. J. Yang, and M. Taghizadeh, "Wear at microscopic scales and light loads for MEMS applications," Wear, vol. 181-183, no. 1, pp. 426-435, 1995. 

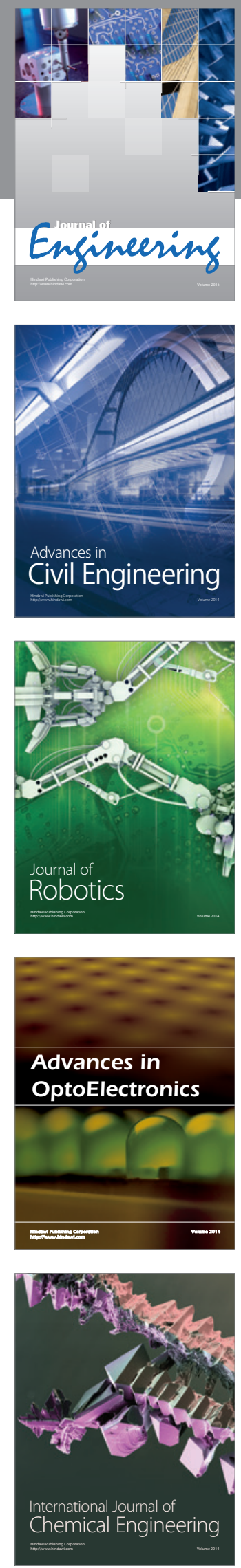

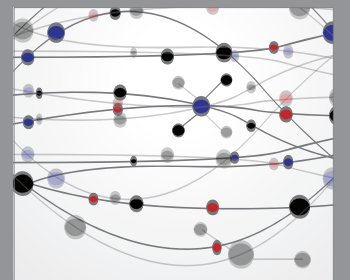

The Scientific World Journal
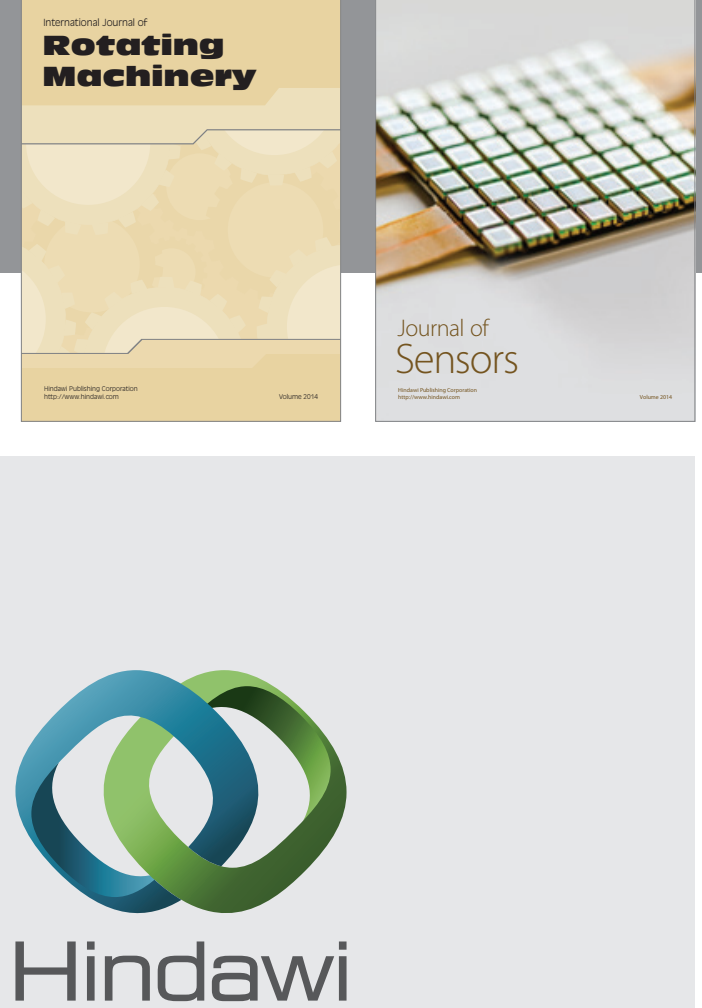

Submit your manuscripts at http://www.hindawi.com
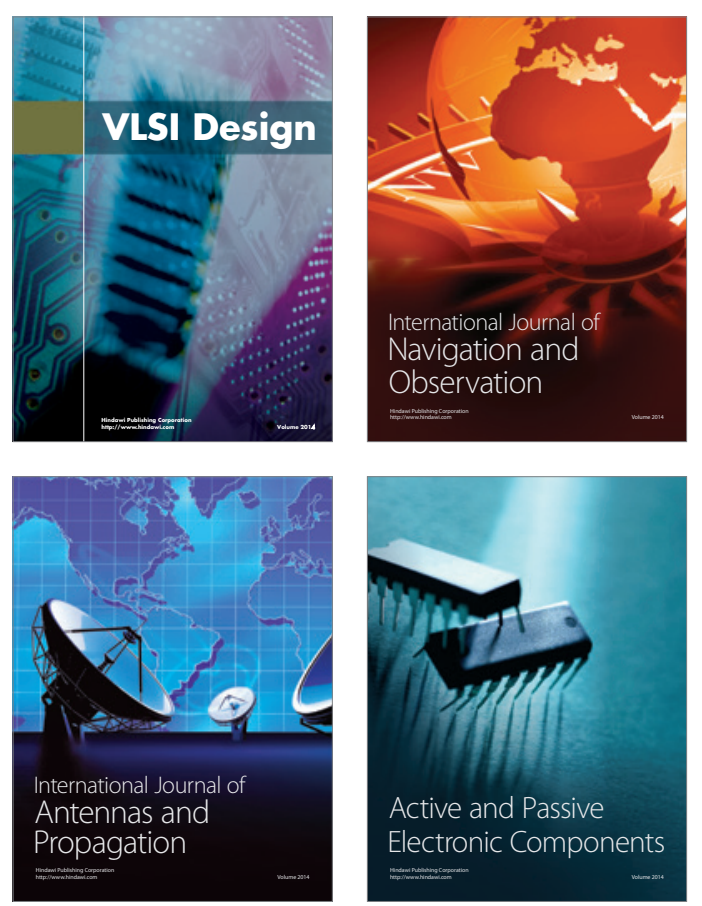
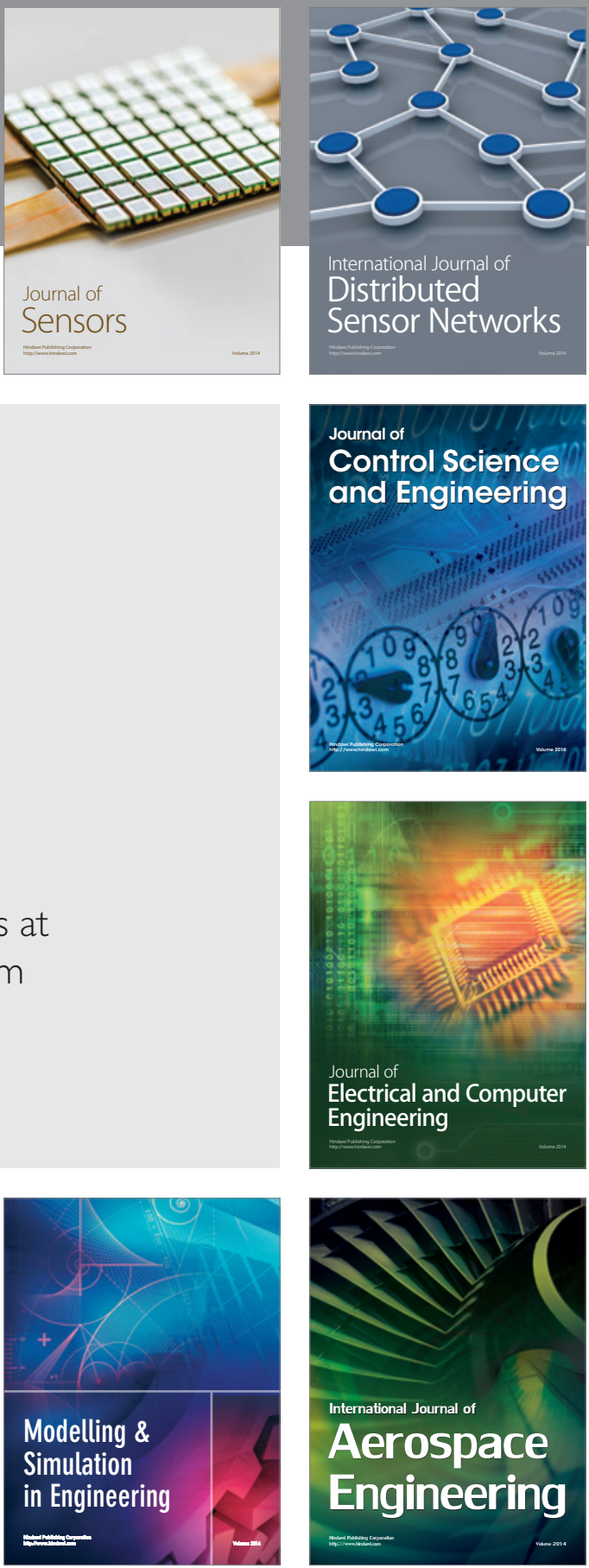

Journal of

Control Science

and Engineering
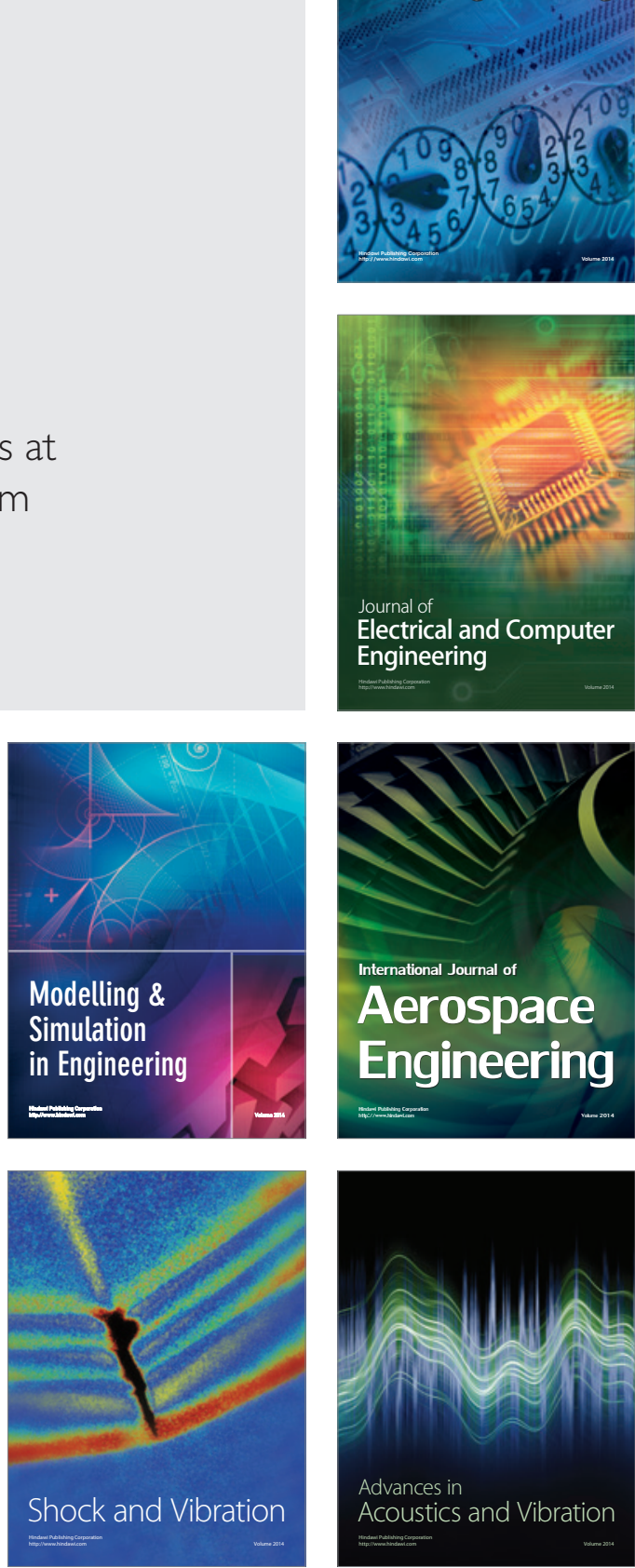